\title{
Moisture content as a design and operational parameter for fast pyrolysis
}

Frederico Gomes Fonseca*a,b ${ }^{*}$ Axel Funke ${ }^{a}$, Andreas Niebel ${ }^{\mathrm{a}}$, Ana Paula Soares Dias ${ }^{\mathrm{b}}$, Nicolaus Dahmen ${ }^{\mathrm{a}}$

* frederico.fonseca@kit.edu

a: Institute of Catalysis Research and Technology (IKFT), Hermann-von-Helmholtz-Platz 1,

D-76344 Eggenstein-Leopoldshafen, Germany

b: LAETA, IDMEC, Instituto Superior Técnico, Universidade de Lisboa, Av. Rovisco Pais, 1, 1049-001 Lisboa, Portugal

\section{Highlights}

1. Wheat straw of three different moisture contents were subjected to fast pyrolysis

2. In contrast to expectations, drying of feedstock led to lower organic oil yields

3. These experimental results were used to model product distribution in Aspen Plus ${ }^{\circledR}$

4. Pyrolysis gas can theoretically supply the heat demand of the process

5. Alternatively, a dryer can be integrated using waste heat for feedstock drying 


\begin{abstract}
Fast pyrolysis trials of wheat straw were performed in a pilot plant featuring a screw reactor and two stage condensation system. Trials differed in the moisture content of the used biomass $(1.2 \%$, 9.2\%, and 23.6\%) and the sweeping gas flowrate. Higher moisture feedstock seems to lead to higher bio-oil production but the largest organic liquid yield occurred at intermediate feedstock moistures. Increasing the sweeping gas flow rate at the system leads to a higher liquid yield richer in organics. Based on these results it is concluded that the highest organic liquid yield is not observed for dry feedstock because the missing water vapour leads to longer hot vapour residence time, favouring secondary gas phase cracking reactions.

Information and yields obtained at the pilot were scaled up to industrial scale $\left(500 \mathrm{~kg} \cdot \mathrm{h}^{-1}\right.$ of feedstock) and used to construct an Aspen Plus ${ }^{\circledR}$ model that can be used to estimate heat availability in different parts of the system as well as simulate a dryer that would employ available internal process heat. This model was used to investigate the impact of using moister feedstock in the process. Enough heat is available for drying moist feedstock by using flue gas of the heat carrier loop in a different manner as in the current design.
\end{abstract}

\title{
Keywords
}

Fast pyrolysis, biomass moisture, process simulation, biomass drying, Aspen Plus. 


\section{Introduction}

The use of biomass as a feedstock for sustainable fuel production has been in controversial discussion due to the potential conflict between food \& feed and energy crop cultivation on the available arable land and the increased emissions of greenhouse gases from changes in land use [1]. Lignocellulose raw materials, such as wood or wheat straw, have great potential for biorefining while not competing with food production. Conversion products from lignocellulosic materials such as e.g. fuels, intermediates, or fine chemicals, can theoretically compete in the traditional petrochemicaldominated market [2].

Fast pyrolysis (FP) is a thermochemical conversion process that has been extensively applied for degradation of bio-based feedstocks. This process features high heating rates, very short hot product vapour residence times, and fast condensation systems to recover produced liquid phases. The conversion is characterized by a high liquid yield, named fast pyrolysis bio-oil (FPBO), and smaller fractions of solids and non-condensable gases. [3]

In the bioliq $^{\circledast}$ process, fast pyrolysis is considered a pre-treatment step to produce an intermediate fuel that is suitable for gasification [4]. This way, a decentralized concept can be applied where fast pyrolysis units convert biomass residues regionally, while a pressurized, entrained flow gasifier and synthesis unit can be realized in industrial scale $[5,6]$. For the case of a common agricultural residue in Europe such as e.g. wheat straw it was found that around one-third of the energetic content of the feedstock is recovered in a synthetic fuel that can be readily used as $2^{\text {nd }}$ generation drop-in biofuel in existing engines [7].

Regarding the condensation system to produce the desired liquid phase, the bioliq ${ }^{\circledR}$ fast pyrolysis process employs two consecutive condensation loops. Both loops recirculate the condensate and employ it as entrainer for the incoming vapours. The first stage, the organic-rich condensate (OC), operates at around $90^{\circ} \mathrm{C}$ and a subsequent electrostatic precipitator warrants the recovery of the formed aerosols. The second stage operates at around $30^{\circ} \mathrm{C}$ and produces an aqueous condensate (AC). 
The quality requirements of the produced FPBO are substantially lower as compared to direct combustion applications. The main concern is the production of a pumpable slurry to feed the gasifier, i.e. solid and water content are two critical parameters [4]. In the FPBO, a fraction of water between $15-35 \%$ is expected, depending on the moisture content of the usually air-dry feedstock [8]. The water content of the FPBO should be kept as low as possible for direct combustion applications, increasing bio-oil stability and energy density while at the same time decreasing transportation costs and acidity $[8,9]$. On the one hand, water lowers the heating value, increases ignition delay, and decreases the combustion rate. On the other hand, it is recommended to adjust a water content between 10 and ca. $25 \%$ by weight because it reduces the FPBO viscosity and leads to a more uniform temperature profile during combustion [9]. Research has pointed to the control of the water content of the FPBO by tuning the moisture content of the feedstock; however, the cost of drying raises questions regarding its economic feasibility [8].

It follows that water content of the FPBO, amongst other parameters, is an important characteristic for both combustion and gasification applications. One important parameter that directly affects the water content of the produced FPBO is the moisture content of the feedstock. Any water contained in the feedstock will inevitably be evaporated during the process [10]. This results in an increased heat demand, a change in the heating up of the particles, and additional water in the product. Therefore, the feedstock is often dried to a moisture content below $10 \%$ wt. prior to feeding to the pyrolysis reactor [11].

Experiments have shown that an increase in moisture content leads to an increase in char and gas production $[8,12-14]$. Studies at a single particle level show that the effective reaction temperature lowers with increasing moisture contents, attributed to the fact that more heat is spent for drying during heating up. Lower pyrolysis temperature promotes charring reactions in contrast to condensable vapor production $[8,15]$. Also, it was observed that the FPBO yield is less affected and that the amount of reaction water is reduced with higher moisture content [12]. It should be noted that this observation is highly dependent on the way FPBO yield is being reported. When the yield of 
FPBO is reported on a dry basis, additional water may lead to an increase in FPBO oil yield at the expense of organics, which are the desired product [12]. It was also observed that steam favors the formation of polar organic compounds at the expense of char and gas yields, possibly due to better removal of volatiles from the solid matrix and stabilization of radicals [16]. There are also contrasting results presented; e.g. it was shown that the moisture content does not seem to impact the char yield while decreasing the FPBO yield for experiments conducted with bamboo, pulp and paper, and polystyrene [17].

A decrease in reaction water may be reasoned with lower hot vapor residence time due to the additional steam formed in the reactor. This will lead to a higher volume flow rate and a reduction of secondary cracking reactions, such as thermal cracking, re-polymerization, and re-condensation, which are known to decrease the yield in organics by producing additional char, gas, and reaction water [12,18-22]. Gas yield increases with increasing sweeping gas flow due to the removal of condensable volatiles from the reaction zone, whereas the char yield diminishes. Longer residence times lead to an increased occurrence of the aforementioned reactions, favouring the formation of carbon deposits [16]. Bio-oil yields have also been positively correlated with the sweeping gas flow rate $[18-21,23]$.

When simulating pyrolysis processes to reflect above discussed changes in product distribution, it is desirable to model detailed reaction kinetics to fully exploit the advantage of flowsheet simulations. This is not possible for biomass pyrolysis due to the complexity of the feedstock and reaction network, even if the system is reduced to lumped species [2][24]. On the one hand, there is an increased understanding of the multi-component decomposition reactions by applying thermogravimetry to study their kinetics [25]. On the other hand, the suitability of such data to simulate real reactors is limited because of the different particle morphology (pulverized samples vs shreds or pellets) and heat transfer mechanisms [26]. This strategy has been applied both for a single feedstock [27] as well as for varying feedstock composition at different temperatures with a more elaborate subroutine to calculate yields [28]. It is also possible to calculate yields based on minimizing Gibbs free energy in the reactor [29,30], where the biomass is previously 'decomposed' into 
lignocellulosic pseudocomponents or into the constituent elements. This strategy is feasible and used for the modelling of processes that reach thermodynamic equilibrium (such as gasification or slow pyrolysis), and/or situations with few different chemical species. Ward et al. [30] mentions the infeasibility of any reactor model other than a 'black-box' system for processes that involve solid, liquid, and gas phases with individual components. Using either empirical correlations or experimental results, the 'black box' type of model enable the use of a great range of species while avoiding a complexity of setting up a rigorous model.

\subsection{Motivation and objectives}

Commercial applications of fast pyrolysis for production of bio-oils from biomass have been realized, such as Envergent (USA, CAN), BTG (NL), and Mesto/Fortum (FIN). These employ the secondary products (char and pyrolysis gas) as fuels to power the heat demand of the endothermic FP process. In the case of the bioliq ${ }^{\circledR}$ concept, the produced char represents a feedstock for the downstream gasification process, which means it should not be used to supply the heat demand of the FP process. In this sense it is important to make sure that there is enough process heat to run the pyrolysis process. At the same it may be desirable to employ feedstock with varying moisture content to increase supply flexibility. In such a case the evaluation of integrating a drier in the fast pyrolysis process by using available heat sinks becomes important, specifically in combination with the expected changes in process heat demand.

The aim of this study is to analyze the impact of feedstock moisture content on the process design of a fast pyrolysis plant. Special attention is paid to drying requirements and process heat utilization for the case of wheat straw as feedstock, which is currently used as a model agricultural residue. While there is some information regarding the influence of moisture content on fast pyrolysis product distribution as discussed in the Introduction, less data exists about effects on FPBO composition. Research by Demirbas [31], Greenhalf et al. [32] and Scott et al. [33] was focused on wheat straw as a feedstock, but either do not vary the moisture content or only consider the final 
product distribution. Also, data should be obtained from a unit that can be regarded representative for the industrial process under investigation.

In this work, data provided by two units is being used. The realized bioliq ${ }^{\circledR}$ FP pilot plant operates with a feedstock feed rate up to $500 \mathrm{~kg} \cdot \mathrm{h}^{-1}$ and employs a natural gas furnace to produce flue gas used to simultaneously heat up and convey the heat carrier for the reactor loop (quartz sand). The Process Development Unit $\left(10 \mathrm{~kg} \cdot \mathrm{h}^{-1}\right)$ employs electrical heating and a bucket elevator and uses steel beads as a heat carrier. This smaller unit is used to investigate the effect of changing feedstock and process conditions on the product distribution. The mass balances are then used for creating an Aspen Plus $^{\circledR}$ model combined with the design specifications and operational experience of the larger pilot plant.

The first part of this study investigates the effect of wheat straw moisture content on fast pyrolysis yields experimentally in above mentioned process development unit for fast pyrolysis. Special attention is paid on producing consistent results on product composition in a fractionated condensation system to better describe effects of the amount of water present in the reactor and condensation system.

The varying product distribution determined by the experiments with different moisture contents is then used to set up a process simulation in Aspen Plus in the second part of this study. By combining experiments with process simulation in such manner, a consistent model is achieved for the first time to investigate the impact of varying moisture content on process design. The model is used to calculate differences in heat sinks and sources throughout the process upon changing the feedstock moisture. The obtained data is evaluated to calculate feasible dryer options by using the heat available in the process and side products such as e.g. pyrolysis gas. 


\section{Materials and Methods}

\subsection{Analytic methods}

After each trial, samples of the biomass, dry solids (char and ash), and both condensates were analyzed.

The moisture content of the biomass and char was measured according to DIN EN 18134-3 (drying at $105^{\circ} \mathrm{C}$ ). For each condensate, volumetric Karl-Fischer titration using methanol with Hydranal Composite- $\mathrm{V}$ was used to determine the water content. The ash content of the biomass and char was analyzed according to DIN EN ISO 18122 . The samples were subjected to $250^{\circ} \mathrm{C}$ for $60 \mathrm{~min}$, followed by $550{ }^{\circ} \mathrm{C}$ for $120 \mathrm{~min}$. Determination of the volatile content of biomass was performed according to DIN EN ISO 18123. The elementary analysis was performed according to DIN EN 15104 for the biomass and the OC, and DIN EN 51732 for the char.

It is required to determine the content of ethylene glycol in the condensate due to the experimental procedure (see below). The quantification of ethylene glycol in the $\mathrm{OC}$ was done using proton NMR. Chemical oxygen demand (COD) for the AC was determined according to the DIN EN 15705; the total organic carbon content (TOC) was measured according to DIN EN 1484. The OC is submitted to extraction with methanol, filtration, and drying to determine its solids content

Higher heating value (HHV) determination for biomass was made according to DIN EN ISO 18125, while for char according to DIN 51900-3, both applying the dynamic mode. No corrections to acid content were performed due to the low amounts of acids formed. The Lower Heating Value (LHV) for both cases was calculated according to Eq. 1 assuming an enthalpy of vaporization of water of 2257 $J \cdot g^{-1}$

$$
L H V_{\text {char }}=H H V_{\text {char }}-\left(\frac{M M_{\mathrm{H}_{2} \mathrm{O}}}{M M_{\mathrm{H}_{2}}} \times \% W_{H}+\% W_{\mathrm{H}_{2} \mathrm{O}}\right) \times \Delta H_{v a p, \mathrm{H}_{2} \mathrm{O}}
$$

The gas composition is measured online through gas chromatography using neon as a tracer. Its volumetric flow rate is also measured through the use of an online flowmeter. 
The stoichiometric oxygen demand was estimated using Eq. 3 assuming the combustion of a generic organic compound (Eq. 2). The water produced by combustion can be estimated using Eq. 4. After that, the LHV of each species can be estimated in a similar way to the char (Eq. 5). The total LHV of the gas is the weighted average of each component (Eq. 6).

$$
\begin{gathered}
C_{x} H_{y} \mathrm{O}_{z}+\left(x+\frac{y}{4}-\frac{z}{2}\right) \mathrm{O}_{2} \rightarrow x \mathrm{CO}_{2}+\frac{y}{2} \mathrm{H}_{2} \mathrm{O} \\
O_{2 \text { demand }, i}=\frac{\left(x+\frac{y}{4}-\frac{z}{2}\right) \times M M_{\mathrm{O}_{2}}}{M M_{i}} \\
w_{i}=\frac{\frac{y}{2} \times M M_{\mathrm{H}_{2} \mathrm{O}}}{M M_{i}} \\
L H V_{i}=H H V_{i}-w_{i} \times \Delta H_{\text {vap }, \mathrm{H}_{2} \mathrm{O}} \\
L H V_{\text {gas }}=\sum_{i} x_{i} L H V_{i}
\end{gathered}
$$

GC-MS analyses of the pyrolysis condensates have been conducted by Thünen Institute, Hamburg, Germany. The method is described in detail elsewhere [34]. 


\subsection{Feedstock}

Wheat straw (Triticum aestivum L.) was supplied by a local farmer (Dörrmann, KraichtalMünzesheim, Germany), collected from a harvest of spring wheat and supplied in large bales (250-300 $\mathrm{kg}$ each). Prior to the experiments, the wheat straw was cut to a particle size of $<5 \mathrm{~mm}$ with a disintegrator (HZR 1300) and a subsequent cutting mill (LM 450/1000-S5-2), both supplied and installed by 'Neue Herbold Maschinen- und Anlagenbau GmbH' (Sinsheim/Reihen, Germany). Analyses of the feedstock are summarized in Table 1.

Table 1: Elementary and moisture content analysis of the As Received feedstock. ar: as received, $d$ : $d r y$.

\begin{tabular}{llllllll}
\hline Water, ar & Ash, $\mathbf{d}$ & Carbon, $\mathbf{d}$ & Hydrogen, $\mathbf{d}$ & Nitrogen, $\mathbf{d}$ & Potassium, $\mathbf{d}$ & Calcium, $\mathbf{d}$ & HHV, \\
\hline$(\%)$ & $(\%)$ & $(\%)$ & $(\%)$ & $(\%)$ & $\left(\mathrm{mg} \mathrm{kg}^{-1}\right)$ & $\left(\mathrm{mg} \mathrm{kg}^{-1}\right)$ & $\left(\mathrm{MJ} \mathrm{kg}^{-1}\right)$ \\
\hline 9.3 & 6.0 & 46.6 & 5.8 & $<0.5$ & 12.600 & 4.000 & 18.4 \\
\hline
\end{tabular}

\subsection{Pyrolysis trials}

Biomass was conditioned in batches of $25 \mathrm{~kg}$ of As Received wheat straw. Drying was performed in a tray batch convection dryer (Memmert Modell 700) overnight at $105^{\circ} \mathrm{C}$. The moistening was achieved by spraying deionized water on piles of As Received wheat straw and letting it sit overnight in air tight barrels. All moisture contents were determined for samples obtained prior to the experiment; the observed values are listed in Table 2.

Table 2: Average moisture contents of the different feedstocks used in the trials (\% wt.).

\begin{tabular}{llll}
\hline & Dry & As Received & Moist \\
\hline Moisture & $1.2 \pm 0.1 \%$ & $9.3 \pm 0.2 \%$ & $23.6 \pm 0.6 \%$ \\
\hline
\end{tabular}

Additionally, the As Received (AR) feedstock was also used for an experiment with increased nitrogen sweep gas flow to investigate the influence of hot vapor residence time. The nitrogen sweep gas flow was increased from $1.3 \mathrm{Nm}^{-1} \mathrm{~h}^{-1}$ to $3.2 \mathrm{Nm}^{-1} \mathrm{~h}^{-1}$ which corresponds to an increase in volume flow by water vapour comparing AR and moist feedstock. In consequence, the change in hot pyrolysis 
vapour residence time between AR feedstock with normal and high nitrogen sweep gas flow is comparable to the change between the AR and moist feedstock.

The feedstock was sampled regularly during the experiments to monitor the input moisture content. Samples were taken from the biomass lock hopper, i.e. directly before biomass is fed into the reactor to account for changes during handling and storage in the silo. Each experiment was conducted at least in duplicates. In case of high uncertainty between two experimental runs, a third was added and the outlier was omitted for evaluation.

The pyrolysis trials were conducted in the process development unit 'Python' with a feed capacity of $10 \mathrm{~kg} \cdot \mathrm{h}^{-1}$ [35]. At the beginning of an experiment pre-conditioned biomass is fed to a buffer silo, which feeds a screw that controls the feed rate to the reactor of about $7 \mathrm{~kg} \cdot \mathrm{h}^{-1}$. The pyrolysis is performed in a thermally isolated twin-screw reactor in which the biomass is mixed with steel beads of $1.5 \mathrm{~mm}$ diameter as a heat carrier. The heat carrier is heated electrically and recirculated around using bucket elevators. The pyrolysis products are fed into a double cyclone system via an exhaust hood on top of the reactor to recover the dry char at reactor temperature.

The pyrolysis vapours enter the first condensation loop where they are quenched with cooled condensate at around $90^{\circ} \mathrm{C}$ forming the $\mathrm{OC}$, which is collected in a first condensation vessel. Uncondensed vapours and gases are directed through an electrostatic precipitator to remove aerosols and particles. The produced condensate is recirculated, cooled down, and re-injected into the quench as quenching medium. To start up this condensation system, ethylene glycol is used because it is readily miscible with the OC. Consequently, the OC produced from the experiments contains a significant amount of ethylene glycol.

The second condensation loop to recover the AC is designed similarly to the first one but operates at lower temperatures of around $15{ }^{\circ} \mathrm{C}$. The start-up medium of this condensate loop is water. The remaining non-condensable gas is removed and analyzed by an online gas chromatograph before being disposed of. 
Both quenching systems are emptied at the end of each trial. Both condensates and char are weighed and sampled. Yields of the condensates are calculated by discounting the initial water/ethylene glycol filling.

The reactor is heated up by starting the preheated heat carrier cycle and biomass feeding is started once a reactor temperature of $500 \pm 5{ }^{\circ} \mathrm{C}$ was reached. It takes around 10 min to ramp up biomass feeding to the desired feed rate. One can safely assume that pyrolysis operates in steady state as the reactor temperature is reached prior to start up and maintained throughout the runtime at $500 \pm 5{ }^{\circ} \mathrm{C}$. The condensation temperature in the first loop starts at $70^{\circ} \mathrm{C}$ and it takes typically around $20 \mathrm{~min}$ in order to reach the desired condensation temperature of $90 \pm 5^{\circ} \mathrm{C}$. The second condenser does not experience significant temperature changes during start up/ operation and is kept at $15 \pm 2{ }^{\circ} \mathrm{C}$.

\subsection{Estimation of reactor energetic demand}

The heat carrier employed by the pilot plant is quartz sand with a nominal heat capacity of $1.25 \mathrm{~kJ} \cdot \mathrm{kg}^{-1} \cdot \mathrm{K}^{-1}$. The plant operates with a nominal flow rate of sand of 50:1 the amount of biomass. Assuming an average temperature loss over the reactor of $20 \mathrm{~K}$ [36], the heat demand of the reactor could be estimated to be $173 \mathrm{~kW}$ or around $1.25 \mathrm{MJ} \cdot \mathrm{kg}^{-1}$. This value, however, does not take into consideration heat losses nor the effect of different moisture contents on the energetic demand.

Henrich et al. [36] estimated the specific heat demand of different biomasses $\Delta h_{p y r o, a r}$, employing the smaller process development unit (which was also used for the experiments reported here). From these values, they were able to predict the specific heat demands of water-free biomasses $\Delta h_{\text {pyro,bd }}$ using Eq. 7.

$$
\Delta h_{p y r o, b d}=\frac{\left(\Delta h_{p y r o, a r}-w \cdot \Delta h_{w}\right)}{(1-w)}
$$

The value for $\Delta h_{w}$ that brings the water from a liquid at $20^{\circ} \mathrm{C}$ to a vapour at $500{ }^{\circ} \mathrm{C}$ was estimated as $3.39 \mathrm{MJ} \mathrm{kg}^{-1} ; w$ represents the water content (\% wt.). The value thereby calculated for 
the water-free wheat straw results to $1.25 \mathrm{MJ} \mathrm{kg}^{-1}$. By employing the same Eq. 7 it becomes possible to estimate the specific heat for the desired moisture contents

It is also possible to estimate the specific heat demand of the process based on the difference in temperature observed for the heat carrier in the results of the experiments presented here $(\Delta T)$. As the process development unit operates at a biomass feed rate of around $10 \mathrm{~kg} \cdot \mathrm{h}^{-1}$ and the Aspen Plus models employ a flow rate of $500 \mathrm{~kg} \cdot \mathrm{h}^{-1}$ it is necessary to rescale the flow rate of the heat carrier (Eq. 8).

$$
\bar{F}_{H C, \text { pilot }}=F_{\text {bio,pilot }} \frac{F_{H C, \text { Python }}}{\left(\frac{m_{\text {bio,Python }}}{t_{\text {trial }}}\right)}
$$

$\bar{F}_{H C \text {,pilot }}$ corresponds to the rescaled heat carrier flow rate, $F_{\text {bio,pilot }}$ to the target biomass flow rate $\left(500 \mathrm{~kg} \mathrm{~h}^{-1}\right)$, and $F_{H C, P y t h o n}$ to the observed heat carrier flow rate in the process development unit $\left(1200 \mathrm{~kg} \mathrm{~h}^{-1}\right)$. The real biomass flow rate verified on the Python trials is calculated using the total biomass used $\left(m_{\text {bio,Python }}\right)$ and the duration of the trial $\left(t_{\text {trial }}\right)$.

The calculation of the specific enthalpy of the process was conducted with Eq. 9 using data from the experiments. The heat capacity of the heat carrier $\left(c_{p}\right)$ was assumed to be $447 \mathrm{~J} \mathrm{~kg}^{-1} \mathrm{~K}^{-1}$.

$$
\Delta h_{\text {pyro,Python }}=\frac{\bar{F}_{H C, p i l o t} \cdot c_{p} \cdot \Delta T \cdot t_{\text {trial }}}{m_{\text {bio,Python }}}
$$

The values required to apply these equations can be found in the Supplemental Information.

\subsection{Aspen Model}

\subsubsection{Basic bioliq $^{\oplus}$ model}

Aspen Plus simulations of the FP system were made to estimate heat losses and demands on different points of the pyrolysis process (see Figure 1 for a flow scheme). The aim is to estimate possibilities of heat recovery for the implementation of a dryer (which is not available in the pilot plant today) minimizing energy consumption. A previous model of the FP unit limits the chemical species considered to gases, not addressing the complexity of the liquid phases [37]. The present model addresses this situation by the introduction of several additional non-ideal substances that represent 
the majority of the species detectable on the liquid phases by GC-MS, while ignoring any possible high molecular weight residue undetectable by said method. The compositions of the liquid phase were estimated from the GC-MS results from a previous bioliq ${ }^{\circledR}$ FP campaign in May 2015 (details see Supplemental Information) [38]. The composition of the gas phase was based on online GC measurements. The reactor was modelled using an RYIELD unit block based on these experimental results (see Supplemental Information for detailed parameters). As already reported in the introduction, the use of a reactor other than a 'black-box' is not feasible for complex processes involving solid, liquid, and gas phases. The model attempts to echo the stream temperatures and flow rates to allow a rigorous assessment of the stream properties and heat capacities. For the As Received case, stream flow rates and therefore products distribution and temperatures were estimated from values reported from previously mentioned bioliq ${ }^{\circledR}$ campaign. Values for the Dry and Moist cases were estimated through proportionality from the experimental results obtained in the present study. The experimental results were scaled up from the scale of the experiments (around $25 \mathrm{~kg}$ over $3 \mathrm{~h}$ periods) to a pilot scale of $500 \mathrm{~kg} \cdot \mathrm{h}^{-1}$ wheat straw feed rate. Simulations assumed steady state had been reached.

Both straw and char, as non-conventional solids in Aspen Plus, were characterized using the DCOALGEN model to calculate the heat of formation and the specific heat. For both substances, the LHV was supplied (see the Supplemental Information). In the case of straw, the heat capacity was provided with a value of $2021 \mathrm{~J} \cdot \mathrm{kg}^{-1} \cdot \mathrm{K}^{-1}$. The employed equation of state was UNIFAC. The starting flow rate of straw was set to $500 \mathrm{~kg} \cdot \mathrm{h}^{-1}$ which reflects the reality of the bioliq ${ }^{\circledR}$ pilot plant. The values of the straw stream input to the reactor as well as the target values of the downstream exits are reported in the Supplemental Information. 


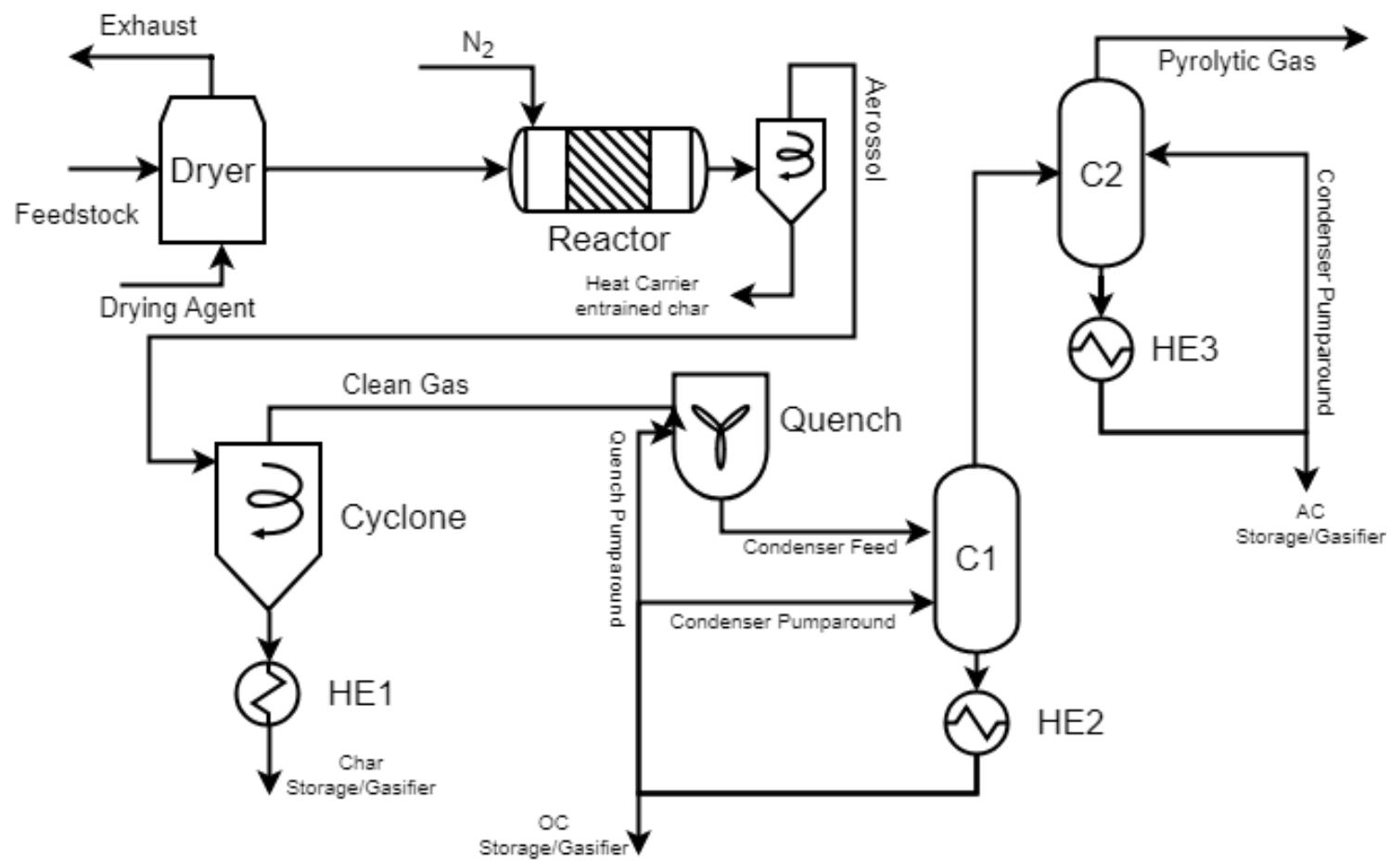

Figure 1: Simplified scheme of the basic Aspen Plus simulation flowsheet.

Associated to the reactor is a first CYCLONE model designed to emulate the separation of the chars that are entrained on the heat carrier loop and contribute to the heat supply. The CYCLONE unit block is set to Solids Separation mode while existent coolers that employ cooling water at different temperatures are simulated by heat exchangers (HE). The char is cooled by a HEATER unit block (HE1). The yielding gas/vapour phase is forwarded to the first condensation loop.

The scheme in Figure 1 only differs from the Aspen simulation in that stream splits were modeled using SPLIT unit blocks (left out in the figure to increase readability). Through this, a more rigorous description of the condenser behavior is achieved, in which a large quantity of fluid is pumped around in order to quench the pyrolysis gases when compared to the amount produced.

The quench was simplified as a Mixer unit block, set at $80^{\circ} \mathrm{C}$. The condensers (C1 and C2) are also simplified as FLASH2 unit blocks, operating at $90^{\circ} \mathrm{C}$ and $28{ }^{\circ} \mathrm{C}$, respectively. In both cases, the condensed liquid phase is cooled down using HEATER unit blocks (HE2 and HE3, respectively); a fraction is recovered as product stream (either OC or AC, see Supplemental Information) and the remaining liquid is pumped around according to the scheme in Figure 2 . In the case of the first condensation loop, the pumparound is split: one fraction is directed to the quench, while the second 
is directed to the condenser. This setup represents the actual design and operation of the bioliq ${ }^{\circledR} \mathrm{FP}$ pilot plant.

\subsubsection{Air pre-heating and drying}

Atmospheric air moisture content was considered an important factor for correct estimations of flue gas quality and dryer operation. The fresh air is assumed to be $15^{\circ} \mathrm{C}$ at a relative humidity of 77\% based on local annual averages. A drying scheme based on a single-stage direct dryer without recirculation was introduced and two options for drying agents were considered. The first option employs atmospheric air (Air Drying model) and the second flue gas (Flue Gas model). In both cases, the biomass is preheated in a heater block and the dryer exhaust is used to pre-heat the atmospheric air (HEATX block). A FLASH2 unit block operating at adiabatic conditions was employed to simulate the expected condensation. The DRYER unit block was simulated in Shortcut adiabatic mode, which only requires the target moisture content to be set. A temperature gap of $5{ }^{\circ} \mathrm{C}$ between the inlet hot stream and the outlet cold stream was assumed for the integration of the dryer exhaust.

Wheat straw as a material is prone to fire hazard due to the low moisture content and the amount of dust present. This danger is kept to a minimum when the temperature of the material is kept well below its self-ignition temperature $\left(220^{\circ} \mathrm{C}\right)$ [39]. A maximal final air temperature of $170^{\circ} \mathrm{C}$ was set according the current heuristics recommending a gap of $50 \mathrm{~K}$ [40].

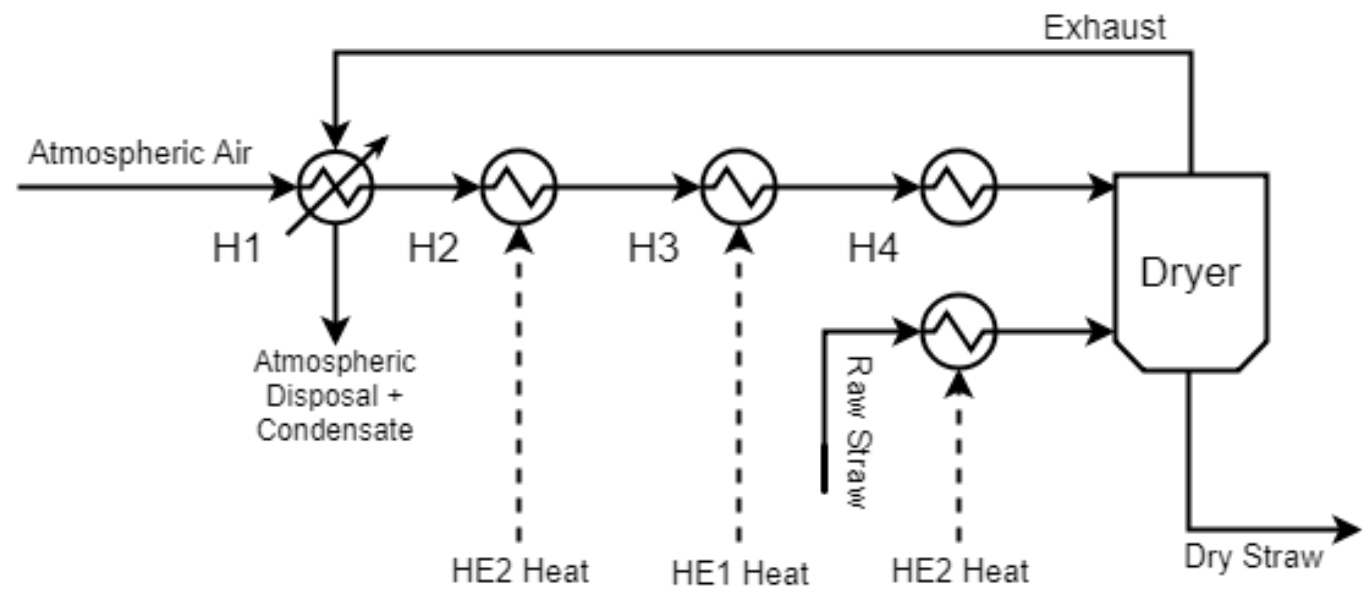

Figure 2: Simplified scheme of the air pre-heating system implemented in Aspen Plus. Solid lines represent material streams, while dotted lines represent heat streams. 
The Air Drying model (Figure 2) employs a total of three heaters, apart from the integration with the exhaust (H1). The second heater ( $\mathrm{H} 2)$ employs heat from the first condenser (HE2), the third heat (H3) from solids cooling (HE1) and the fourth (H4) uses an undisclosed source of heat, such as e.g. flue gas or fuel burning. The heat from the second condenser (HE3) was not employed because its heat is available at a too low temperature.

Calculator unit blocks were employed to ensure that the air moisture was kept constant when varying the air flow and to split the available heat from the HE2 between pre-drying the feed and the air. Design spec blocks were employed to warrant a dryer solid output of $500 \mathrm{~kg} \cdot \mathrm{h}^{-1}$ by varying the total biomass feeding rate, as well as ensuring the maximum temperature of the second heat exchanger would not exceed $80^{\circ} \mathrm{C}$.

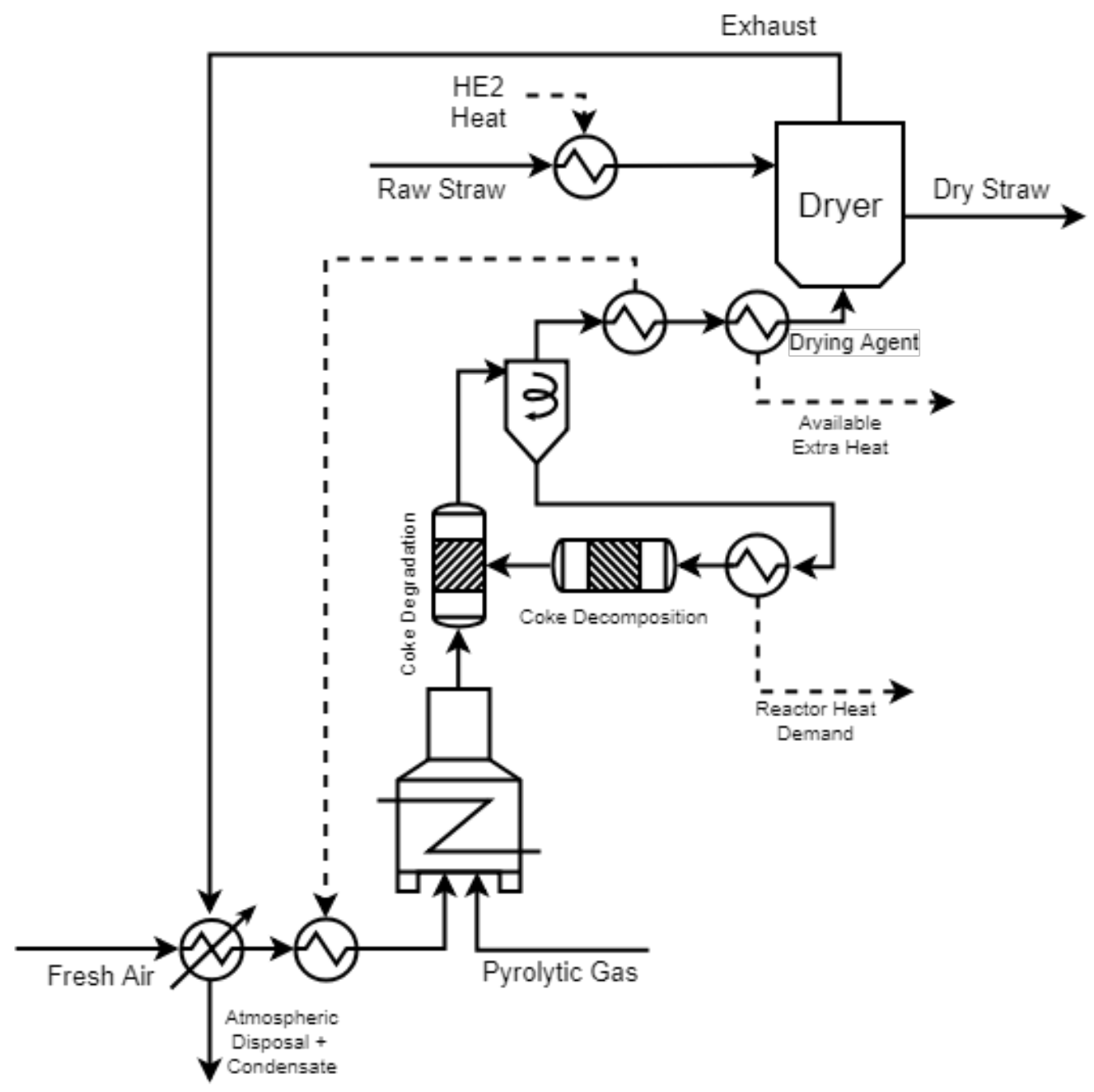

Figure 3: Simplified scheme of the flue gas heating system implemented in Aspen Plus. Solid lines represent material streams, while dotted lines represent heat streams. 
The Flue Gas model (Figure 3) only resembles the Air Drying one in the dryer and feedstock pre-heating. It integrates the dryer to the heat carrier loop of the pyrolysis unit by using the sensible heat of the flue gas exiting the heat carrier loop.

The combustion of the pyrolytic gas in the furnace is modeled as an RGIBBS unit block at a set temperature of $910^{\circ} \mathrm{C}$. This block employs Gibbs energy minimization at adiabatic operation to estimate chemical equilibria and final yields. The heat carrier, modelled as solid $\mathrm{SiO} 2$, includes a fraction of char (the same composition as the one separated in the cyclone after the reactor, see Figure 1), and is fed to an RYIELD block coupled with a FORTRAN routine that decomposes the char into elementary components. This heat carrier runs in a loop from the reactor to a lift pipe and back to the reactor. The flue gas from pyrolysis gas combustion and the heat carrier meet in a second RGIBBS unit operating at $589^{\circ} \mathrm{C}$, which represents the lift pipe. The char is degraded in this unit according to the design of the bioliq ${ }^{\circledast}$ pilot plant. The heat of char oxidation plus the heat from the flue gas warrant that the heat carrier reaches the correct temperature. The solids are separated in an SSPLIT unit block and the gas is cooled down twice. First, it heats up the fresh combustion air using an HEATX model. Second, it is cooled down to $170^{\circ} \mathrm{C}$ to comply with the aforementioned fire hazard limits. As with the Air Drying model, the exhaust of the dryer is cooled down with the fresh combustion air and disposed of atmospherically. It is noted that the heat carrier is not actually cooled and recirculated to provide heat to the reactor in contrast to the illustration in Figure 3 as these are separate Aspen models.

\subsubsection{Sensitivity analysis for determination of optimal conditions}

Sensitivity analyses were conducted in order to select an optimum for both the Flue Gas Drying and the Air Drying models. These analyses were conducted using the Sensitivity tool in Aspen Plus.

Table 3: Sensitivity analysis variables, their ranges, and interval.

\begin{tabular}{lll}
\hline Variable & Range & Increment \\
\hline Fresh Air Flow Rate (kg/h) & $100-3500$ & 100 \\
\hline Biomass Pre-Heating (kW) & $0-18.3 / 23.4^{\text {a }}$ & 5 \\
\hline Extra Heat (H4) (kW) & $0-25$ & 5 \\
\hline
\end{tabular}

a: Energy expense required to bring the biomass up to $80^{\circ} \mathrm{C}$, depending on being As Received/Moist biomass. 
The most relevant parameters analyzed were the temperature of the air at each heating stage and the relative humidity of the exhaust air, ensuring that values over $100 \%$ would not be reached (see Table 3). This value was estimated from the temperature (T) and dew points ( $\left.T_{D}\right)$ of the exhaust (which are calculated automatically by the software), using a modified August-Roche-Magnus approximation (Eq. 10) [41].

$$
R H=100 \% \times \frac{\exp \left(\frac{17.625 \times T_{D}}{243.04+T_{D}}\right)}{\exp \left(\frac{17.625 \times T}{243.04+T}\right)}
$$

Despite the fresh air flow being the most relevant parameter due to economic and engineering constraints, two other parameters were considered for further analysis: maximization of the use of the HE2 heat and maximization of the dryer efficiency (Eq. 11) [42].

$$
\varepsilon=\frac{m_{W, v a p} \times \Delta H_{v a p}}{Q_{\text {sup }}}
$$

In the equations above, $m_{W, v a p}$ stands for the water removed in the dryer, and therefore $m_{W, v a p} \times \Delta H_{\text {vap }}$ represents the power the drying fluid requires to supply. $Q_{\text {sup }}$ stands for the sum of all heat supplied by heaters $\mathrm{H} 2, \mathrm{H} 3$, and $\mathrm{H} 4$.

For the case of the Flue Gas model no sensitivity analysis was conducted and the lowest fresh air amount that would assure the maximum relative humidity of the exhaust air (keeping the limit of max. $100 \%)$ was taken as the optimum point. 


\section{Results and discussion}

\subsection{Fast pyrolysis trials}

The as-received moisture content was found to be $9.3( \pm 0.3) \%$ by weight for all experiments (see also Table 1). After drying, moisture content was $1.2( \pm 0.1) \%$ and $1.2( \pm 0.4) \%$ by weight for the duplicate experiments. Naturally, moistening was less accurate and resulted in a moisture content of $24.0( \pm 1.5) \%$ and $23.2( \pm 1.7) \%$ by weight. Especially the high heterogeneity of the moisture content in this latter case does have a significant effect on dry and carbon balances of the experiments. After the moisture content was evaluated for the 'Moist' case, the nitrogen flow rate was adjusted to account for the increase in volume flow from the As Received to the Moist feedstock experiments due to steam release by $1.9 \mathrm{~m}^{3} \mathrm{~h}^{-1}$ at normal conditions.

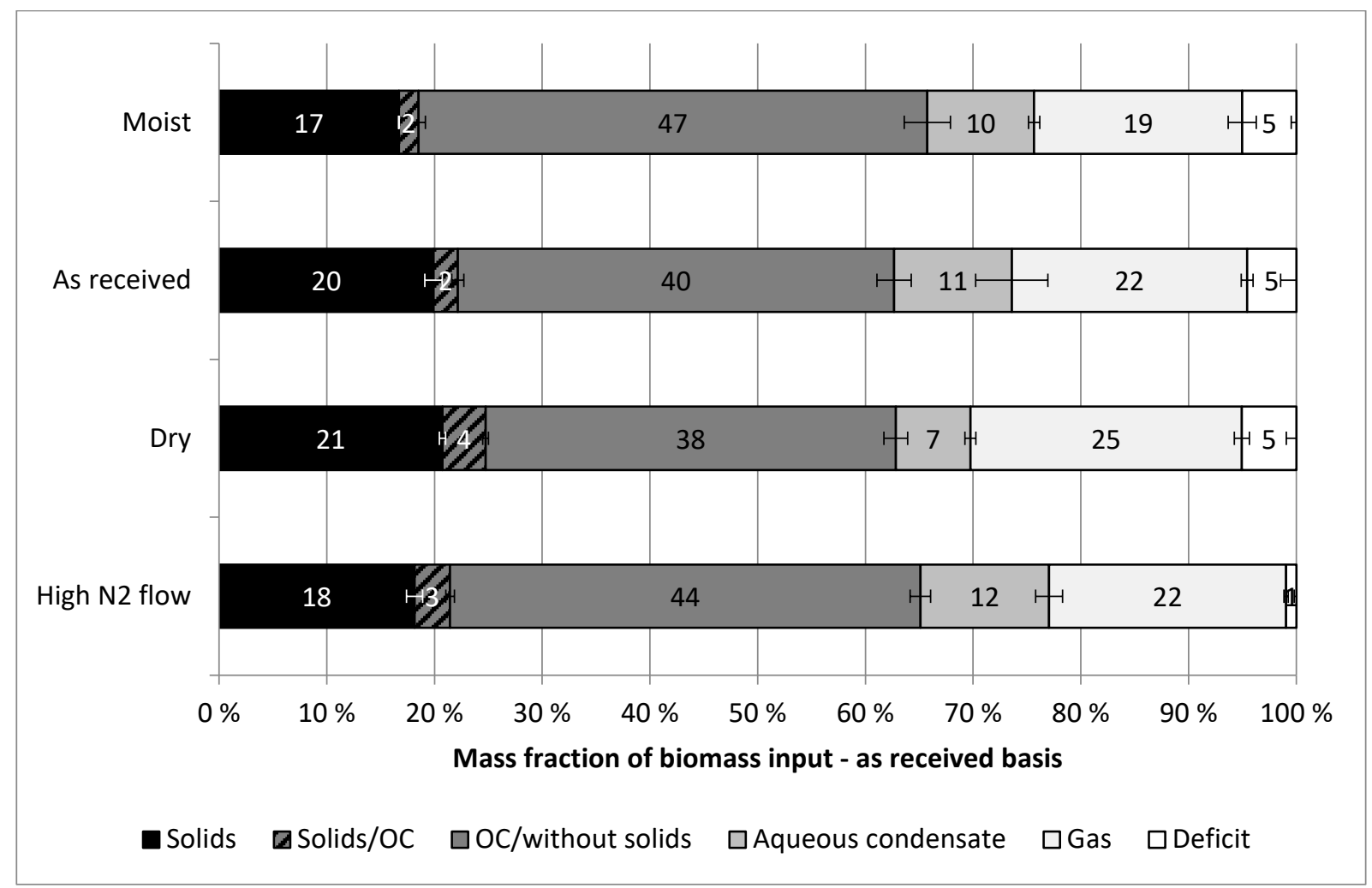

Figure 4: Yields of the different product phases expressed as a mass fraction of the biomass input (asreceived basis). Solids/OC corresponds to the solids fraction present on the organic-rich condensate, analysed as the fraction that is not soluble in methanol. 
Mass balance closure of the experiments was between 95-101\% (see Figure 4). Losses in the mass balance are likely due to light volatiles in the pyrolysis gas that is neither condensed at final condenser temperature $\left(20^{\circ} \mathrm{C}\right)$ nor detected by the online $\mathrm{GC}$ for gas analysis. It is noted that mass balances are only overestimated for the case of increased nitrogen flow. At the same time, gas yields are as high as in the base case. This is unexpected since the oil yield is significantly higher and gas yield should, therefore, be lower. The amount of non-condensable gas is measured by a constant tracer (neon gas) that is used to calibrate the peak areas of the GC measurement and the uncertainty associated with this method increases when the tracer is diluted - as is the case with increased nitrogen flow. It is likely that the overestimation of the mass balance is due to an overestimation of the gas flow for the case of the experiments with high nitrogen flow rate.

Yields of char and non-condensable gas increase with decreasing moisture content on an asreceived basis (Figure 4). This would be expected, as fewer organic material is present in the biomass feedstock with higher moisture contents. At the same time, the presence of water in the reactor would lead to steam cracking reactions that would increase gas contents and decrease the amount of larger organic molecules. The amount of $O C$ and $A C$ rises, which again is an effect of this kind of balance because any moisture present in the feedstock will add to the yield of condensate. The FPBO yield for the as-received case is in the same range as results from experiments in a fluidized bed reactor which were reported to be between 47.5 and $60.6 \%$ by weight [43]. When comparing the effect of the sweeping gas flow to the base case experiment one can observe a rise in condensate yield while the solids and gas yield stays constant. This is in line with the expectation that a reduction of hot vapour residence time reduces secondary cracking reactions [44]. While the as-received balance is not very suitable to compare the different process conditions, it does deliver the required basis for the flowsheet simulations that are described further below. 


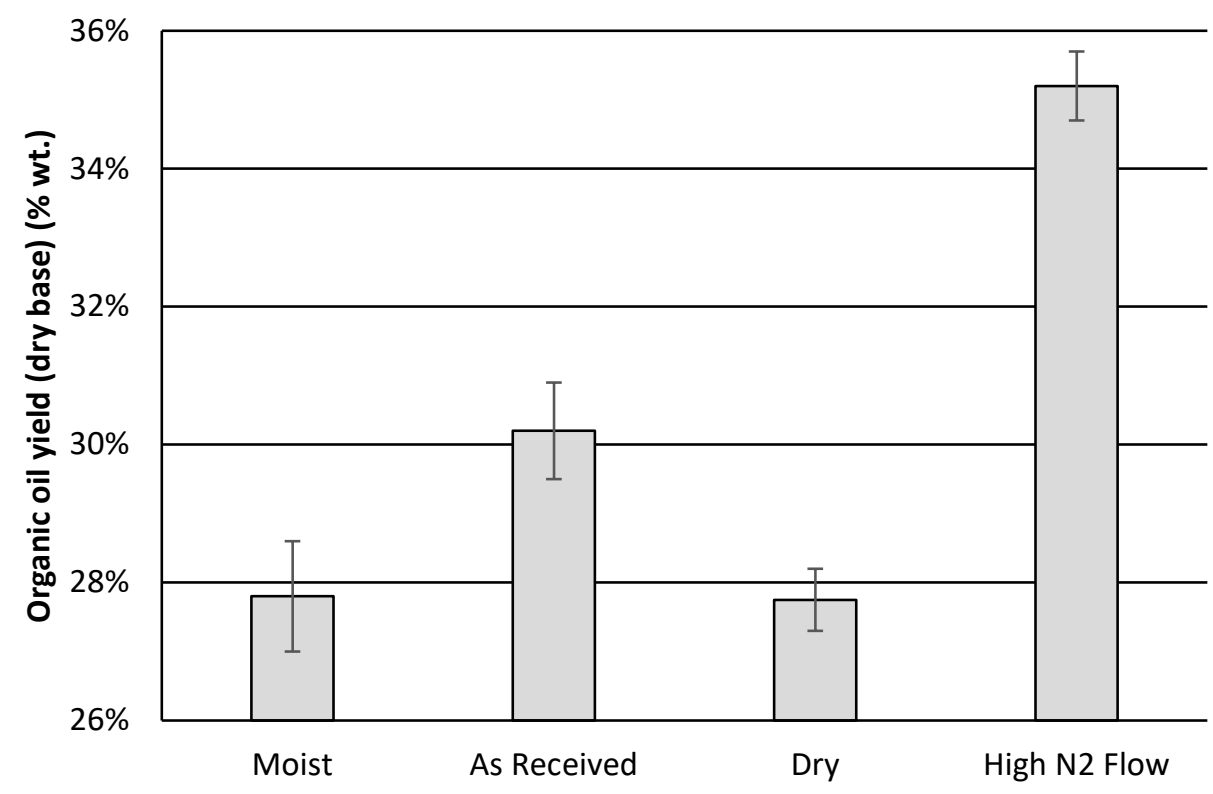

Figure 5: Organic yield expressed on a dry basis.

When analyzing the results in Figure 5, it is noted that the deviation between the duplicate experiments with Moist feedstock is significantly higher than for all other runs. This effect is attributed to the high water content in the process which lowers the precision of balances, especially of the organic oil yield calculation. The low organic oil yield observed in the experimental runs is generally in line with results reported elsewhere and primarily a result of the feedstock's high ash content $[32,34,45]$

Recent experiments with wheat straw with the same experimental setup resulted in lower organic oil yield but in that case, the ash content was significantly higher and it is concluded that the results are still consistent [46]. Surprisingly, the results deviate significantly from experiments with wheat straw from the same source but a different harvesting year [47]. Although the previously used wheat straw has slightly higher ash content, also the organic oil yield is higher. This could be explained by the difference in the harvesting year and/or feedstock lot because straw exhibits a high heterogeneity compared to wood (without bark). In addition to the potential difference in feedstock characteristics, some changes in experimental procedure might add to the observed effects: 1) the pipe connection between cyclone and quench was exchanged in the meantime to one with a larger 
diameter, thus increasing the vapour residence time and 2) the nitrogen supply was refurbished and simultaneously the flow rate reduced to almost $50 \%$.

When considering the situation of the high $\mathrm{N}_{2}$ flow, a substantially higher organic oil yield than in all other three cases can be observed. This can be attributed to a shorter residence time and, therefore, a lesser extension of cracking reaction.

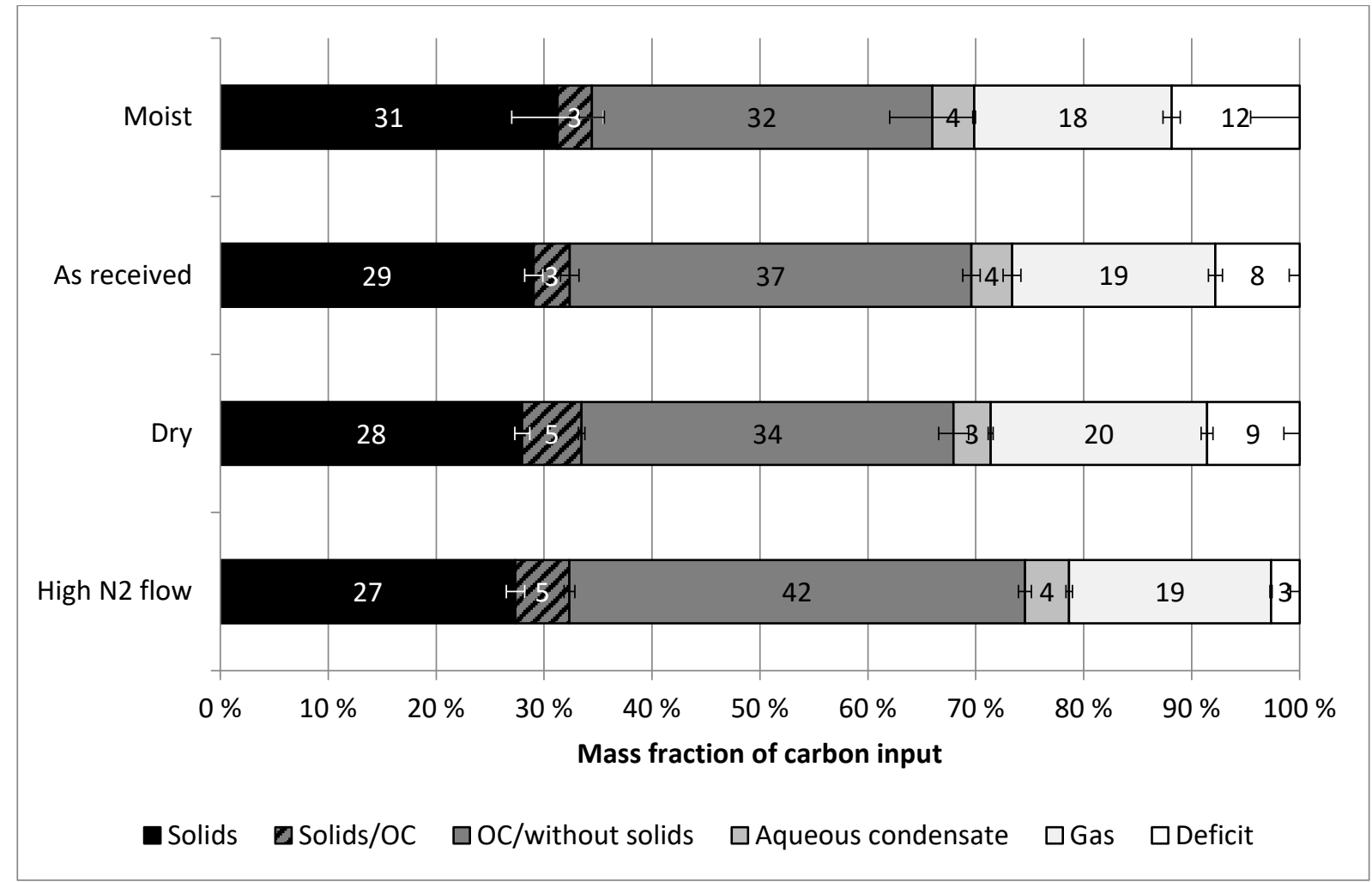

Figure 6: Distribution of carbon between the product phases expressed as mass fraction of carbon input.

The results for the organic oil yield contradicts the expectation that organic oil yield increases with biomass dryness because the heating rate, and hence the temperature at which primary pyrolysis takes place inside the biomass particle, is increased. This becomes even more evident when evaluating carbon balances (see Figure 6). It can be observed that for both Dry and Moist wheat straw less carbon is recovered in the FPBO than for the As Received case. Additionally, it can be concluded that for the Moist feedstock fewer dehydration reactions have taken place because relatively less carbon is recovered in the oil as compared to the base case while the organic oil yields are about the same for 
both cases. This observation can be explained by the influence of hot vapour residence time on the product distribution and a change in thermodynamic equilibria for dehydration reactions [13]. The higher the moisture content, the higher the steam load in the system and the shorter the hot vapour residence time. The results of the experiments indicate that there is an optimization problem for the moisture content of the feedstock with regard to primary pyrolysis temperature and hot gas residence time. It is furthermore concluded that this optimum must be somewhere in between a moisture content of 1 and $24 \%$ by weight for the case of wheat straw, i.e. the As Received case does not necessarily reflect this optimum in oil yield. This is an important consideration for an existing pyrolysis installation because the equipment size that determines hot vapour residence time is usually fixed.

The hypothesis that hot vapour residence time is affecting the organic oil yield is supported by trials using increased nitrogen flow. Especially the residence time with solids that contain minerals plays a significant role in secondary polymerization/charring reactions [44]. This situation is the case in the experimental setup employed here because vapour needs to flow inside the reactor and subsequently to the cyclones prior to solid removal. It is expected that the hot vapour residence time is below $1 \mathrm{~s}$, but the experimental results presented in this manuscript indicate that this short residence time already has a significant impact on the formation of condensable products.

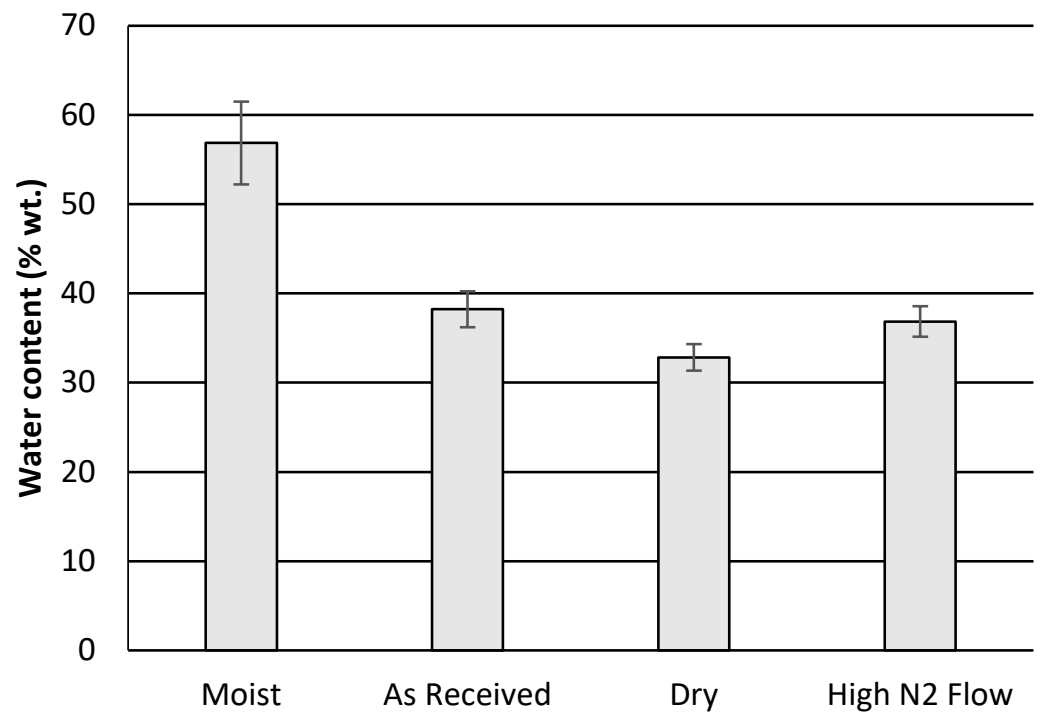

Figure 7: Water content as a fraction of the organic-rich condensate. 
The moisture content of the biomass (Figure 7) leads to a big impact on the water content of the OC, especially comparing the Moist and the As Received cases. An increase in water content is expected because the equilibrium in the first condenser is heavily influenced by a larger fraction of water vapour [8][48]. For the runs with increased $\mathrm{N}_{2}$ flow rate, it is observed that the $\mathrm{OC}$ water content is in the same range as the As Received and Dry situation. The carry-over of water vapour due to the higher sweeping gas flow rate might explain the higher AC fraction in this situation (see Figure 4) and the lower hot vapour residence times might have led to a lower occurrence of steam cracking reactions that would help decrease this water content.

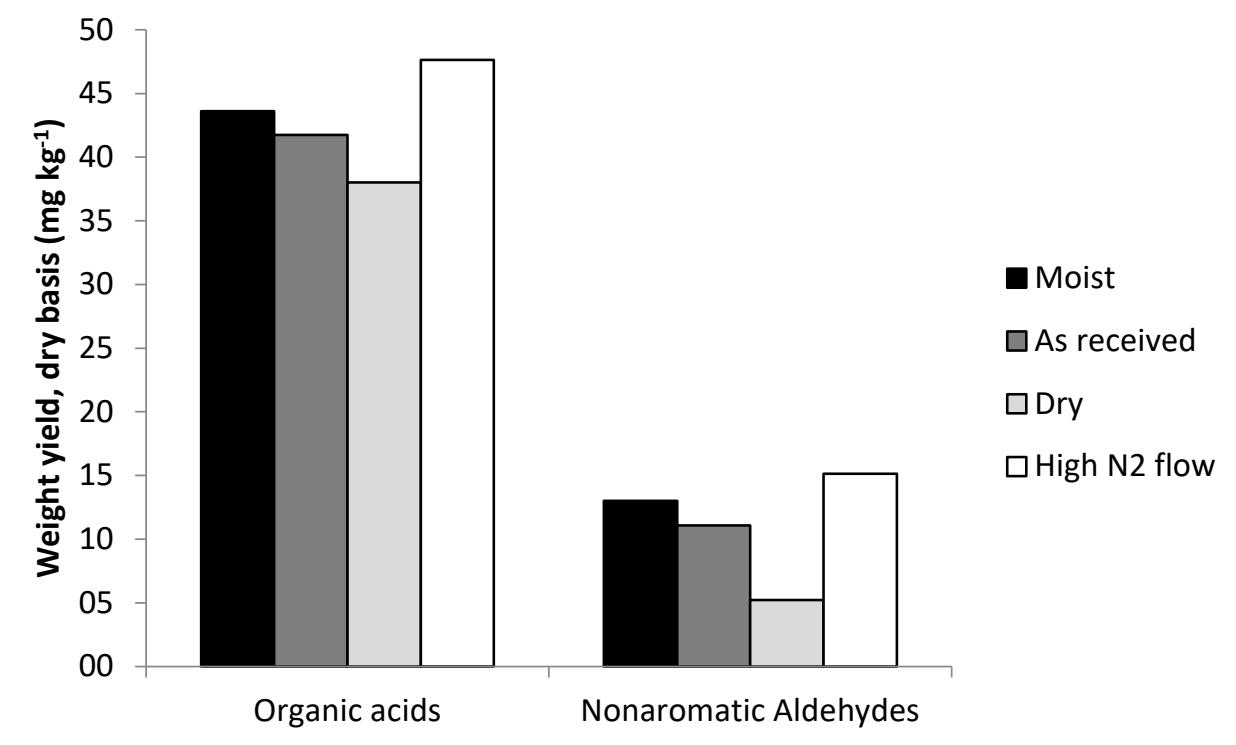

Figure 8: Yield of GC detectable compounds, expressed as mass fraction of biomass input (dry basis).

Around $50-56 \%$ of the organic compounds could be detected by GC/MS. It has to be noted that the interpretation of this data has to be treated with care due to the chosen experimental setup because of the design of the condensation. Both condensates are recirculated to cool down fresh incoming vapours. Especially the $\mathrm{OC}$ is recirculated at around $80-90^{\circ} \mathrm{C}$, which leads to aging reactions of the produced condensate during the process. In the bioliq ${ }^{\circledR}$ pilot plant, a mean residence time of around 6 hours was determined for the condensate due to this recirculation, by which a kind of artificial aging is obtained [38]. The duration of this aging may differ up to one hour between experimental runs due to differing durations of the biomass feeding. The only substances that show 
obvious trends are organic acids, which almost exclusively consist of acetic and propionic acid, and non-aromatic aldehydes, which almost exclusively consist of hydroxyacetaldehyde (Figure 8). Average yields of other major substances from the total of the experiments reflect a typical composition of FPBO from wheat straw and are as follows [34]: organic acids $42.8( \pm 4.0) \mathrm{mg} \mathrm{kg}^{-1}$, non-aromatic aldehydes $11.1( \pm 4.3) \mathrm{mg} \mathrm{kg}^{-1}$, non-aromatic ketones $45.5( \pm 3.0) \mathrm{mg} \mathrm{kg}^{-1}$, furans $8.0( \pm 1.6) \mathrm{mg} \mathrm{kg}^{-1}$, phenols $5.3( \pm 1.2) \mathrm{mg} \mathrm{kg}^{-1}$, guaiacols $10.4( \pm 3.0) \mathrm{mg} \mathrm{kg}^{-1}$, syringols $5.4( \pm 1.5) \mathrm{mg} \mathrm{kg}^{-1}$, and anhydrosugars $10.9( \pm 2.3) \mathrm{mg} \mathrm{kg}^{-1}$; all values are reported on dry feedstock basis.

From Figure 8 it can be observed that the amount of produced organic acids and non-aromatic aldehydes decreases with increasing hot vapour residence time (hot vapour residence time increases as follows: high $\mathrm{N}_{2}$ flow < moist < as received < dry). Organic acids are considered to be largely stable in homogeneous secondary pyrolysis reactions [49]. However, solids are removed outside the reactor and significant heterogeneous solid/vapour residence time has to be assumed. Reduction of organic acids by heterogeneous cracking reactions has also been reported elsewhere [50], which explains the observed trend from Figure 8 . Non-aromatic aldehydes are known to be readily degraded at temperatures around $500{ }^{\circ} \mathrm{C}$, which is the temperature in the downstream section of the reactor [44]. 


\subsection{Process simulation}

The aim of the Aspen simulations is to calculate heat flows in the fast pyrolysis process. The model was adapted to reflect the experimentally determined mass flows, i.e. there are no deviations between experiment and model due to the applied method of creating the Aspen model (see Supplemental Information for detailed input parameters). One important task was the representation of the condensation stages and the pressures used in the individual liquid-vapour separation (FLASH2) unit blocks had to be set considerably lower than real values in order to achieve good agreement with experimental results. The pyrolysis plant operates slightly below atmospheric pressure whereas this value had to be lowered in the simulation to $860 \mathrm{kPa}$ and $95 \mathrm{kPa}$ for the first and second condensers, respectively. This significant difference reflects a shortcoming of the chosen UNIFAC model. Despite this effort, the species distribution in the streams was fairly close to the ones observed experimentally, with deviations of major compounds $<20 \%$ in almost all cases (see Supplemental Information for details). It is concluded that the derived heat streams represent a solid basis for further evaluation.

\subsubsection{Process heat demand}

Based on the experimental results, the process heat demand and how it can be covered with pyrolysis by-products have to be evaluated for varying feedstock moisture contents. The energy demand of the pyrolysis reactor will change with varying moisture content of the feedstock according to the data presented in Table 4.

Table 4: Specific reactor heat demands per mass of feedstock $\left(\mathrm{MJ} \mathrm{kg}^{-1}\right)$.

\begin{tabular}{ccc}
\hline & Eq. 7 & Experiments \\
\hline Dry & 1.28 & 1.38 \\
\hline As Received & 1.45 & 1.33 \\
\hline Moist & 1.75 & 1.61 \\
\hline
\end{tabular}

The values obtained by the formula (Eq. 7 [36]) show how the heat demand of the reactor increases with moisture content because more heat must be supplied to evaporate water from the biomass in addition to supplying the heat of reaction for pyrolysis. The results obtained from the 
pyrolysis experiments presented in this study deviate from this trend in that there is an unexpected increase in heat demand from the As Received to Dry case. This effect could be explained with a change in the heat of reaction for pyrolysis. An increase in the temperature at which primary pyrolysis takes place is expected at lower moisture content. Higher primary pyrolysis temperature leads to more liquid products being formed and consequently to a higher heat demand for pyrolysis. However, the experiments conducted here are not suitable to support this hypothesis and the observed increase in heat demand between the As Received and Dry case might also be due to experimental error.

It is also noted that the estimations performed using Eq. 7 consider the presence of bed heating and heat losses on the reactor, while the estimations from the experiments presented here are solely based on the loss of temperature experienced by the heat carrier over the length of the reactor. In that sense, the values obtained through Eq. 7 seem to yield a more consistent result than the ones derived from our experiments and will be used in the subsequent calculations.

\subsubsection{Aspen Simulations: calculation of heat flows}

The heat demand of the reactor is supplied by the heat carrier, which in turn is heated by three main heat inputs to the bioliq ${ }^{\circledR}$ fast pyrolysis process. First, hot flue gas heats and lifts up the heat carrier so that it can flow back to the reactor. For ease of operation, combustion of natural gas is used in the bioliq ${ }^{\circledast}$ pilot unit to provide this hot flue gas. The second heat input is partial combustion of char which is entrained in the heat carrier cycle to help sustain and control the temperature of the heat carrier. For the case of As Received wheat straw an amount of around $15 \mathrm{~kg} \cdot \mathrm{h}^{-1}$ is combusted to serve this purpose. Third, a constant flow of $32 \mathrm{~kg} \cdot \mathrm{h}^{-1}$ of slightly superheated steam at 5 bar is employed to assist the transportation of the heat carrier. This corresponds to a heat demand of $24.6 \mathrm{~kW}$.

The developed Aspen Plus model was used to calculate the major heat sources and sinks resulting for the design of the bioliq ${ }^{\circledR}$ pilot (the results are summarized in Table 5). Three cases were calculated for wheat straw with the investigated different moisture contents, reflecting the experimentally observed changes in product distribution and composition. It is desirable that the heat demand of the process should be primarily covered by combusting the pyrolysis gas, which is a by- 


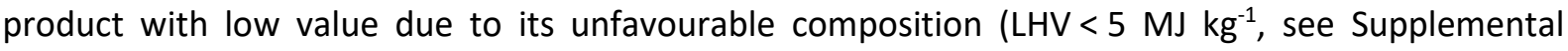
Information). A furnace efficiency of $80 \%$ [51] was assumed for the furnace. Only if additional heat is required, char was considered to assist heat supply to the process (notwithstanding the combustion of entrained char for temperature control purposes).

It is obvious that the Dry case leads to the most favourable energy consumption. In that case it could even be feasible to cover the heat demand for steam production with the pyrolysis gas. All of the produced char would then be available for gasification within the bioliq ${ }^{\circledR}$ concept or other potential applications [52,53]. These observations may prove important advantages for the Dry case even though less organic liquids are produced. It is noted that these advantages only come into full effect if the heat demand for drying incoming feedstock can be covered by the currently unused internal heat sources, which are represented by the heat exchangers in the product recovery section (see Table 5). Currently, these are operated with cooling water connected to a secondary air fan cooler. The results from the Aspen simulations show that the biggest changes in available heat for the different feedstock moisture contents are in the $\mathrm{OC}$ heat exchanger, i.e. the additional water vapour in the process has a significant impact in the first condensation stage. Of the heat sources, only HE1 presents a working temperature that could be used to produce conventional process heat through the use e.g. of process steam. The downside is that it presents the lowest energy availability of the three. The temperature range of HE3 means that its heat is not useful for any immediate applications despite the significant energetic potential. Flue gas from the liftpipe is another heat source in the process but currently used to preheat incoming combustion air.

Finally, it is noted that even for the As Received case no additional natural gas is required to fuel the heat carrier cycle, meaning that most of the required process heat can be covered by pyrolysis gas and a minor fraction of the char. Similar results were observed for the case of grape residues, but it was also reported that it heavily depends on the type of feedstock employed [54]. 
Table 5: Relevant heat sources and sinks resulting from Aspen simulation of the fast pyrolysis process.

Details to char and gas flows can be found in the Supplemental Information.

\begin{tabular}{|c|c|c|c|}
\hline & Dry & As Received & Moist \\
\hline Overall Heat Demand (kW) & 221 & 252 & 305 \\
\hline Heat Input by Steam Supply (kW) & 25 & 25 & 25 \\
\hline Heat by Entrained Char Combustion (kW) & 126 & 121 & 98 \\
\hline Remaining Heat Demand (kW) & 70 & 106 & 182 \\
\hline Pyrolytic Gas Required (mass fraction) & $73 \%$ & $99 \%$ & $100 \%$ \\
\hline Char Required (mass fraction) & 0 & 0 & $10 \%$ \\
\hline \multicolumn{4}{|l|}{ Unused Heat Sources } \\
\hline HE1: $515-20^{\circ} \mathrm{C}(\mathrm{kW})$ & 22 & 22 & 16 \\
\hline HE2: $90-84^{\circ} \mathrm{C}(\mathrm{kW})$ & 105 & 107 & 123 \\
\hline HE3: $30-28^{\circ} \mathrm{C}(\mathrm{kW})$ & 62 & 63 & 63 \\
\hline
\end{tabular}

\subsubsection{Aspen Simulations: biomass drying}

The experimental results of this work (chapter 3.1) indicate that biomass feedstock with lower moisture content leads to an increased production of char and gas, while producing lower amounts of OC with lower water content. On the one hand these observations do not appear to favour the drying of biomass feedstock prior to fast pyrolysis, on the other hand Dry feedstocks would reduce the energy expenditure in the pyrolysis process. As shown above this could lead to the case where all auxiliary energy can be supplied by combusting the by-product pyrolysis gas. Moreover, it may be desired to control the moisture content in the produced OC and/or to maximize the solid by-product in regard to gasification fuel production which essentially is the main focus of the bioliq ${ }^{\circledast}$ process [4]. Based on these considerations the integration of a dryer in the pyrolysis process is investigated with the aim to use waste heat within the plant. The three investigated moisture contents (Table 2, and throughout the previous sections) are reflected in this consideration, with the water removed and energy input presented in Table 6. 
Table 6: Water removal and its energy demand in the dryer, the enthalpy of vapourization of water was assumed to be of $2257 \mathrm{~kJ}^{\mathrm{kg}} \mathrm{kg}^{-1}$.

\begin{tabular}{ccc}
\hline & Water Removed $\left(\mathbf{k g} \cdot \mathrm{h}^{-1}\right)$ & Energy Dryer $(\mathrm{kW})$ \\
\hline Moist $\rightarrow$ Dry & 146.2 & 91.6 \\
Moist $\rightarrow$ AR & 93.6 & 58.7 \\
AR $\rightarrow$ Dry & 44.3 & 27.8 \\
\hline
\end{tabular}

As stated before (section 2.5.2), two models of drying were considered: Air Drying and Flue Gas Drying. The first (Figure 2) employs a series of heaters that utilize existent waste heat $(\mathrm{H} 2, \mathrm{H} 3$, which represent heat from the char and OC heat exchangers, respectively) followed by a final heater that is powered by an external source $(\mathrm{H} 4)$ to bring the mass of air to the optimum temperature. The latter (Figure 3) uses the flue gas from the liftpipe prior to preheating the fresh combustion air (which is the current use of the flue gas).

The main parameter varied during the analysis of this system is the minimum amount of fresh air that ensures a maximum relative humidity of the dryer exhaust inferior to $100 \%$ (to avoid saturation and condensation). For the case with air drying, the heat supplied to the heater $\mathrm{H} 4$ was modified as a second parameter. The range of parameter variation is explained in the Method Section (Table 3).

\section{Air Drying}

The effect of varying the air flow rate is evaluated by two parameters: the use of heat recovered from the $O C$ condensation loop and the efficiency of the dryer (see Eq. 12). Although it is not the primary controlled variable, the effects of varying the heat supplied to $\mathrm{H} 4$ and the heat carrier preheating create dispersion in the results, often resulting in more than one valid value for each considered air flow rate. A linear trendline is indicated to ease the analysis of this dispersion; this does not impose any physical meaning on the results. 


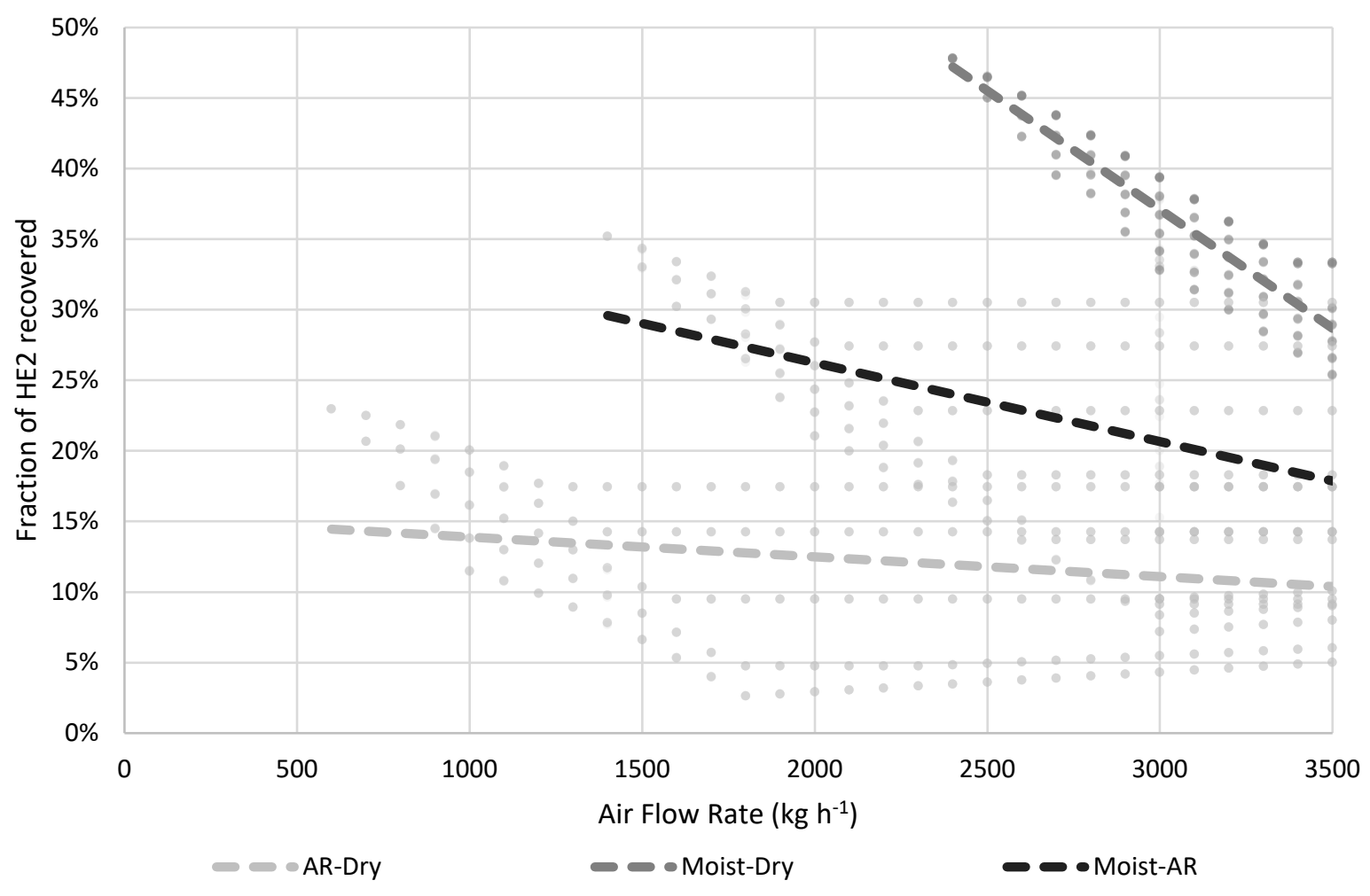

Figure 9: Percentage of the employed HE2 heat as a function of the air flow rate.

Maximizing the use of the process heat (Figure 9) is one of the priorities of this work. All observed maxima coincide with the lowest feasible air flow rate. A low air flow rate implies smaller equipment sizes and lower operating costs. It also has an overall greater influence on the drying process compared to the other investigated variables. For the $A R \rightarrow D r y$ case, the graph indicates a consistently low use of recovered heat because the temperature obtained after recycling dryer exhaust air is very close to the target $80^{\circ} \mathrm{C}$ that would be provided by the HE2 heat. The most demanding case of drying Moist $\rightarrow$ Dry reaches only a maximum heat utilization of $47.8 \%$. Obviously, the temperature of this heat source is too low be fully exploited for drying feedstock. 


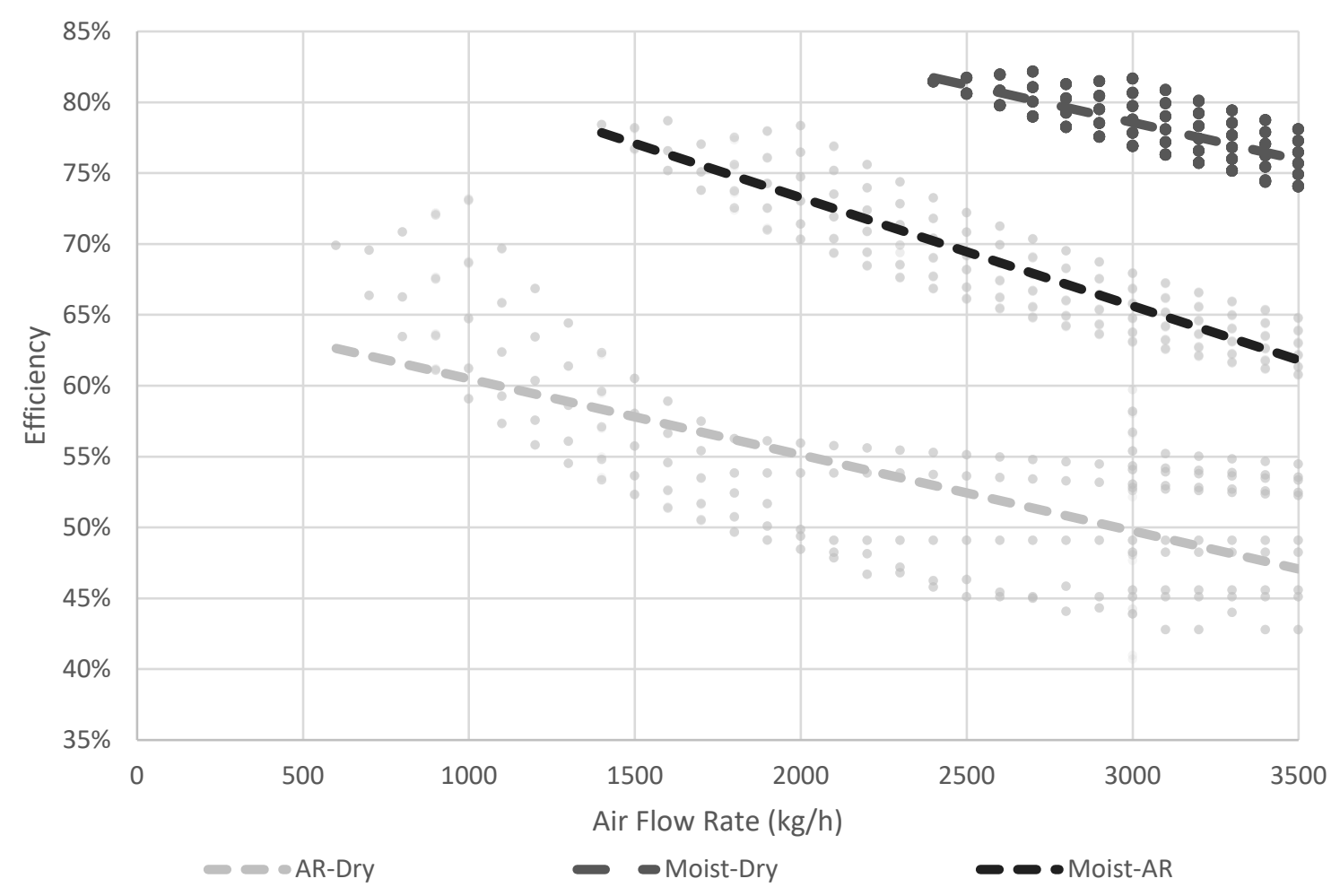

Figure 10: Efficiency of the dryer as a function of the air flow rate.

The efficiency of the drying process (Figure 10) represents the fraction of the energy given to the air that is used to remove water from the biomass. The results indicate that the heat supplied to the air to bring it to the drying temperature is mostly wasted for small moisture content differences, leading to low efficiencies. Again, the minima of each case are at the lowest air flow rate which also coincides with the highest usage of recovered heat.

It can be directly concluded from the sensitivity analysis that all cases with lowest air flow rate represent optimum design choices (see Table 7). It is important to state that the values were considered valid whenever the relative humidity was lower than $100 \%$, thus disregarding the effect of external perturbations or condensation in tubes for design purposes. 
Table 7: Optimum values for the case of 'Air Drying' for all three situations in study.

\begin{tabular}{cccc}
\hline & Moist $\rightarrow$ Dry & Moist $\rightarrow$ AR & AR $\rightarrow$ Dry \\
\hline Temp Biomass $\left({ }^{\circ} \mathrm{C}\right)$ & 80 & 80 & 80 \\
\hline Temp Air $\left({ }^{\circ} \mathrm{C}\right)$ & 170 & 170 & 170 \\
\hline Fresh Air Flow $\left(\mathrm{kg} \cdot \mathrm{h}^{-1}\right)$ & 2400 & 1400 & 600 \\
\hline H4 Heat $(\mathrm{kW})$ & 40.55 & 14.16 & 0 \\
\hline \% HE2 used & 47.8 & 35.2 & 23.0 \\
\hline Wasted HE2 Heat $(\mathrm{kW})$ & 79.91 & 91.72 & 99.42 \\
\hline Wasted HE1 Heat $(\mathrm{kW})$ & 0 & 0 & 15.77 \\
\hline Thermal Efficiency (\%) & 81.5 & 78.4 & 69.9 \\
\hline
\end{tabular}

The results of Table 7 indicate that the potential of HE1 was hard-capped by the temperature limit, which was imposed for safety reasons. None of the cases was able to fully utilize the HE2 heat due to its low temperature level. Larger air masses were able to employ all available HE1 heat, while still requiring extra heat. The case AR $\rightarrow$ Dry did not make use of all the heat provided by HE1 and is the only case that does not require external heat. $\mathrm{H} 4$ extra heat requirements can be potentially achieved by integration with the flue gas (see next section), by combustion of unutilized pyrolysis products (see previous section), or by combusting additional fuels such as e.g. natural gas.

Flue Gas Drying

A study on the viability of using the flue gas resultant from replacing the currently employed natural gas by pyrolysis gas on the furnace was also performed. The values were estimated for a situation of complete combustion, considering that the temperatures and behaviour of the current furnace have not changed. 
Table 8: Optimum values for the case of 'Flue Gas Drying' for all three situations in study.

\begin{tabular}{cccc}
\hline & Moist $\rightarrow$ Dry & Moist $\rightarrow$ AR & AR $\rightarrow$ Dry \\
\hline Fresh Air Flow $\left(\mathbf{k g} \cdot \mathbf{h}^{-1}\right)^{\text {a }}$ & 2300 & 1300 & 500 \\
\hline Excess Heat $(\mathbf{k W})$ & 0 & 0 & 14.17 \\
\hline
\end{tabular}

a: The feedstock is preheated to $80^{\circ} \mathrm{C}$ in order to use part of the HE2 heat.

Enough heat is available to dry incoming feedstock for all cases. The airflow requirements estimated for Flue Gas Drying case are slightly lower than the ones verified for the Air Drying case (see Table 8). These results imply slightly lower operational costs versus the Air Drying case. All estimated air flows are required to achieve a valid relative humidity of the exhaust air below $100 \%$.

It was not possible to keep the temperature limit $\left(170^{\circ} \mathrm{C}\right)$ through heat integration alone for the lowest demand case, requiring a second form of heat removal from the system to comply with the fire hazard values. In this case another high-temperature heat source is created that would be available for other purposes. It is noted that this proposed setup would require the furnace to operate with high excesses of oxygen which renders temperature control by char oxidation impossible. This setup fulfils its purpose within the scope of this study, but it would need some changes (e.g. a second combustion stage) to not interfere with the current operation strategy of the biolig ${ }^{\circledast}$ pilot plant. Furthermore, this setup does provide the heat requirement to dry moist feedstock but it would also limit the use of recovered heat from the process. 


\section{Conclusions}

Fast pyrolysis experiments of wheat straw treated for different moisture contents have been performed with a process development unit. The results indicate that wheat straw treated to be moist (23.6\% water content) led to a lower production of char and gas, and a larger amount of liquids as compared to the use of as received feedstock (9.3\%). Interestingly, it was also observed that dry feedstock (1.2\%) produces less organic-rich condensate than for the case of as received feedstock. This effect may be the result of counteracting effects from varying heat rates due to the heat of evaporation and changes in the hot vapour residence time due to additional steam flow. Experiments with an increased sweeping gas flow rate support this conclusion.

The number of organic acids and nonaromatic aldehydes was observed to increase with the feedstock moisture content, which might indicate the presence of water or the energy demand of its vaporization have a protecting effect preventing the degradation of these compounds. The lower gas residence times in the reactor caused by a greater sweeping flow rate lead to a lower rate of degradation, more effectively than higher feedstock moisture contents.

The experimentally determined product distributions upon changing the feedstock's moisture content have been used to set up a consistent Aspen model for the determination of heat flows within the process. Calculations have shown that the pyrolysis gas, of no commercial value due to a very high inert content, is able to cover the heat demand of the fast pyrolysis reactor for two of the three different feedstock moisture contents. This allows more char to be recovered and subsequently employed for biofuel production via gasification or other alternative uses.

The cooling of char presents a temperature range that would allow for the production of conventional process heat, such as e.g. steam, but with a comparatively low heat availability. The cooling of the first condensation loop was identified as the prime energy source due to a large energy availability even though the usable temperature sets some limits to its use. The lower energetic demands of a process run with a low moisture content biomass paired with an FPBO with lower water content indicate that the integration of a dryer appears to be useful. 
Single stage direct dryers were simulated to reduce the moisture content of the same biomass from a value of $23.6 \%$ wt. to either $9.2 \%$ or $1.3 \%$ wt., and from $9.2 \%$ to $1.3 \%$ wt.. A sensitivity analysis was conducted to investigate the potential use heat sources from the pyrolysis process to integrate the dryer in the process. The optimum points for both Air Drying and Flue Gas Drying options yielded similar results in terms of airflow demand. The first enables a partial use of the available process heat, while requiring an extra source of heat to reach the desired drying temperatures. The latter enables the use of a heat that is currently only employed for preheating of furnace air, but makes little use of other process heat.

\section{Acknowledgments}

The authors thank Daniel Richter and Norbert Sickinger for all technical support, as well as Pia Griesheimer, Jessica Heinrich, Petra Janke and Melany Frank for analytical support.

\section{Bibliography}

[1] B. Kamm, P.R. Gruber, M. Kamm, Biorefineries-Industrial Processes and Products, Wiley-VCH Verlag GmbH, Weinheim, Germany, 2005. doi:10.1002/9783527619849.

[2] P. Basu, Biomass Gasification and Pyrolysis: Practical Design and Theory, Elsevier, 2010.

[3] A. V Bridgwater, Review of fast pyrolysis of biomass and product upgrading, Biomass and Bioenergy. 38 (2012) 68-94. doi:10.1016/j.biombioe.2011.01.048.

[4] T. Nicoleit, N. Dahmen, J. Sauer, Production and Storage of Gasifiable Slurries Based on FlashPyrolyzed Straw, Energy Technol. 4 (2016) 221-229. doi:10.1002/ente.201500273.

[5] N. Dahmen, E. Dinjus, T. Kolb, U. Arnold, H. Leibold, R. Stahl, State of the art of the bioliq ${ }^{\circledR}$ process for synthetic biofuels production, Environ. Prog. Sustain. Energy. 31 (2012) 176-181. doi:10.1002/ep.10624.

[6] N. Dahmen, E. Henrich, E. Dinjus, F. Weirich, The bioliq bioslurry gasification process for the production of biosynfuels, organic chemicals, and energy, Energ Sust Soc. 2 (2012).

[7] F. Trippe, M. Fröhling, F. Schultmann, R. Stahl, E. Henrich, A. Dalai, Comprehensive technoeconomic assessment of dimethyl ether (DME) synthesis and Fischer-Tropsch synthesis as alternative process steps within biomass-to-liquid production, Fuel Process. Technol. 106 (2013) 577-586. doi:10.1016/j.fuproc.2012.09.029.

[8] R.J.M.R.J.M. Westerhof, N.J.M. Kuipers, S.R.A. Kersten, W.P.M. van Swaaij, Controlling the water content of biomass fast pyrolysis oil, Ind. Eng. Chem. Res. 46 (2007) 9238-9247. doi:10.1021/ie070684k.

[9] A. Oasmaa, S. Czernik, Fuel oil quality of biomass pyrolysis oils-state of the art for the end users, Fuel Energy Abstr. 13 (1999) 914-921. doi:10.1016/S0140-6701(00)96592-5.

[10] S. Wang, G. Dai, H. Yang, Z. Luo, Lignocellulosic biomass pyrolysis mechanism: A state-of-theart review, Prog. Energy Combust. Sci. 62 (2017) 33-86. doi:10.1016/j.pecs.2017.05.004. 
[11] M. Van de Velden, J. Baeyens, A. Brems, B. Janssens, R. Dewil, Fundamentals, kinetics and endothermicity of the biomass pyrolysis reaction, Renew. Energy. 35 (2010) 232-242. doi:10.1016/j.renene.2009.04.019.

[12] O.O.O. Beaumont, Y. Schwob, Influence of Physical and Chemical Parameters on Wood Pyrolysis, Ind. Eng. Chem. Process Des. Dev. 23 (1984) 637-641. doi:10.1021/i200027a002.

[13] M.R. Gray, W.H. Corcoran, G.R. Gavalas, Pyrolysis of a wood-derived material. Effects of moisture and ash content, Ind. Eng. Chem. Process Des. Dev. 24 (1985) 646-651. doi:10.1021/i200030a020.

[14] H. Liu, Q. Zhang, H. Hu, A. Li, H. Yao, Influence of residual moisture on deep dewatered sludge pyrolysis, Int. J. Hydrogen Energy. 39 (2014) 1253-1261. doi:10.1016/j.ijhydene.2013.10.050.

[15] S.R. a. Kersten, X. Wang, W. Prins, W.P.M. van Swaaij, Biomass Pyrolysis in a Fluidized Bed Reactor. Part 1: Literature Review and Model Simulations, Ind. Eng. Chem. Res. 44 (2005) 87738785. doi:10.1021/ie0504856.

[16] V. Minkova, M. Razvigorova, E. Bjornbom, R. Zanzi, T. Budinova, N. Petrov, Effect of water vapour and biomass nature on the yield and quality of the pyrolysis products from biomass, Fuel Process. Technol. 70 (2001) 53-61. doi:10.1016/S0378-3820(00)00153-3.

[17] C. Chen, Y. Jin, Y. Chi, Effects of moisture content and $\mathrm{CaO}$ on municipal solid waste pyrolysis in a fixed bed reactor, J. Anal. Appl. Pyrolysis. 110 (2014) 108-112. doi:10.1016/j.jaap.2014.08.009.

[18] E. Pütün, B.B. Uzun, A.E. Pütün, Fixed-bed catalytic pyrolysis of cotton-seed cake: Effects of pyrolysis temperature, natural zeolite content and sweeping gas flow rate, Bioresour. Technol. 97 (2006) 701-710. doi:10.1016/j.biortech.2005.04.005.

[19] E. Pütün, Catalytic pyrolysis of biomass: Effects of pyrolysis temperature, sweeping gas flow rate and MgO catalyst, Energy. 35 (2010) 2761-2766. doi:10.1016/j.energy.2010.02.024.

[20] F. Ateş, E. Pütün, A.E. Pütün, Fast pyrolysis of sesame stalk: Yields and structural analysis of biooil, J. Anal. Appl. Pyrolysis. 71 (2004) 779-790. doi:10.1016/j.jaap.2003.11.001.

[21] D.. Park, E.. Hwang, J.. Kim, J.. Choi, Y.. Kim, H.. Woo, Catalytic degradation of polyethylene over solid acid catalysts, Polym. Degrad. Stab. 65 (1999) 193-198. doi:10.1016/S01413910(99)00004-X.

[22] A. V Bridgwater, A.J. Toft, J.G. Brammer, A techno-economic comparison of power production by biomass fast pyrolysis with gasification and combustion, 2002. doi:10.1016/S13640321(01)00010-7.

[23] J.M. Encinar, F.J. Beltrán, A. Ramiro, J.F. González, Catalyzed Pyrolysis of Grape and Olive Bagasse. Influence of Catalyst Type and Chemical Treatment, Ind. Eng. Chem. Res. 36 (1997) 4176-4183. doi:10.1021/ie960795b.

[24] D. Radlein, A. Quignard, A Short Historical Review of Fast Pyrolysis of Biomass, Oil Gas Sci. Technol. - Rev. d'IFP Energies Nouv. 68 (2013) 765-783. doi:10.2516/ogst/2013162.

[25] E. Ranzi, A. Cuoci, T. Faravelli, A. Frassoldati, G. Migliavacca, S. Pierucci, S. Sommariva, Chemical Kinetics of Biomass Pyrolysis, Energ Fuel. 22 (2008) 4292-4300.

[26] E. Grieco, G. Baldi, Analysis and modelling of wood pyrolysis, Chem. Eng. Sci. 66 (2011) 650660. doi:10.1016/j.ces.2010.11.018.

[27] X. Xianjun, S. Zongkang, M. Peiyong, Y. jin, W. zhaobin, Establishment of Three Components of Biomass Pyrolysis Yield Model, Energy Procedia. 66 (2015) 293-296. doi:10.1016/j.egypro.2015.02.061.

[28] K. Onarheim, Y. Solantausta, J. Lehto, Process Simulation Development of Fast Pyrolysis of 
Wood Using Aspen Plus, Energy \& Fuels. 29 (2015) 205-217. doi:10.1021/ef502023y.

[29] A. Visconti, M. Miccio, D. Juchelková, Equilibrium-based simulation of lignocellulosic biomass pyrolysis via Aspen Plus ${ }^{\circledR}$, in: Recent Adv. Appl. Math. Model. Simul., 2014: pp. 242-251.

[30] J. Ward, M.G. Rasul, M.M.K. Bhuiya, Energy Recovery from Biomass by Fast Pyrolysis, Procedia Eng. 90 (2014) 669-674. doi:10.1016/j.proeng.2014.11.791.

[31] A. Demirbas, Effect of initial moisture content on the yields of oily products from pyrolysis of biomass, J. Anal. Appl. Pyrolysis. 71 (2004) 803-815. doi:10.1016/j.jaap.2003.10.008.

[32] C.E. Greenhalf, D.J. Nowakowski, A.B. Harms, J.O. Titiloye, A. V Bridgwater, A comparative study of straw, perennial grasses and hardwoods in terms of fast pyrolysis products, Fuel. 108 (2013) 216-230. doi:10.1016/j.fuel.2013.01.075.

[33] D.S. Scott, P. Majerski, J. Piskorz, D. Radlein, A second look at fast pyrolysis of biomass-the RTI process, J. Anal. Appl. Pyrolysis. 51 (1999) 23-37. doi:10.1016/S0165-2370(99)00006-6.

[34] N. Charon, J. Ponthus, D. Espinat, F. Broust, G. Volle, J. Valette, D. Meier, Multi-technique characterization of fast pyrolysis oils, J. Anal. Appl. Pyrolysis. 116 (2015) 18-26. doi: 10.1016/j.jaap.2015.10.012.

[35] A. Funke, D. Richter, A. Niebel, N. Dahmen, J. Sauer, Fast Pyrolysis of Biomass Residues in a Twin-screw Mixing Reactor, J Vis. Exp. 115 (2016) e54395. doi:10.3791/54395

[36] E. Henrich, N. Dahmen, F. Weirich, R. Reimert, C. Kornmayer, Fast pyrolysis of lignocellulosics in a twin screw mixer reactor, Fuel Process. Technol. 143 (2016) 151-161. doi:10.1016/j.fuproc.2015.11.003.

[37] F. Trippe, M. Fröhling, F. Schultmann, R. Stahl, E. Henrich, Techno-economic assessment of gasification as a process step within biomass-to-liquid (BtL) fuel and chemicals production, Fuel Process. Technol. 92 (2011) 2169-2184. doi:10.1016/j.fuproc.2011.06.026.

[38] C. Pfitzer, N. Dahmen, N. Tröger, F. Weirich, J. Sauer, A. Günther, M. Müller-Hagedorn, Fast Pyrolysis of Wheat Straw in the Bioliq Pilot Plant, Energy and Fuels. 30 (2016) 8047-8054. doi:10.1021/acs.energyfuels.6b01412.

[39] J.E. Geddie, A Guide to Combustible Dusts, Raleigh, 2012.

[40] Arun S. Mujumdar, Handbook of Industrial Drying, 3rd ed., CRC Press, 2006. doi:10.1080/07373930701399224.

[41] O.A. Alduchov, R.E. Eskridge, Improved Magnus Form Approximation of Saturation Vapour Pressure, J. Appl. Meteorol. 35 (1996) 601-609. doi:10.1175/15200450(1996)035<0601:IMFAOS>2.0.CO;2.

[42] S. Heyne, S. Harvey, Production of synthetic natural gas from biomass-process integrated drying, ECOS 2009 - 22nd Int. Conf. Effic. Cost, Optim. Simul. Environ. Impact Energy Syst. (2009).

[43] N. Jendoubi, F. Broust, J.M. Commandre, G. Mauviel, M. Sardin, J. Lede, Inorganics distribution in bio oils and char produced by biomass fast pyrolysis: The key role of aerosols, J. Anal. Appl. Pyrolysis. 92 (2011) 59-67. doi:10.1016/j.jaap.2011.04.007.

[44] E. Hoekstra, R.J.M. Westerhof, W. Brilman, W.P.M. Van Swaaij, S.R.A. Kersten, K.J.A. Hogendoorn, M. Windt, Heterogeneous and homogeneous reactions of pyrolysis vapours from pine wood, AIChE J. 58 (2012) 2830-2842. doi:10.1002/aic.12799.

[45] S.R.G. Oudenhoven, R.J.M. Westerhof, S.R.A. Kersten, Fast pyrolysis of organic acid leached wood, straw, hay and bagasse: Improved oil and sugar yields, J. Anal. Appl. Pyrolysis. 116 (2015) 253-262. doi:10.1016/j.jaap.2015.09.003.

[46] A. Funke, M. Tomasi Morgano, H. Leibold, N. Dahmen, Experimental Comparison of Fast and 
Intermediate Pyrolysis, J Anal Appl Pyr. submitted (2016).

[47] A. Funke, A. Niebel, D. Richter, M.M. Abbas, A.K. Müller, S. Radloff, M. Paneru, J. Maier, N. Dahmen, J. Sauer, Fast pyrolysis char - Assessment of alternative uses within the bioliq $^{\circledR}$ concept, Bioresour. Technol. 200 (2016) 905-913. doi:10.1016/j.biortech.2015.11.012.

[48] Y. Ille, F. Kröhl, A. Velez, A. Funke, S. Pereda, K. Schaber, N. Dahmen, Activity of water in pyrolysis oil - experiments and modelling, J. Anal. Appl. Pyr. 135 (2018) 260-270. doi:10.1016/j.jaap.2018.08.027.

[49] P. Morf, P. Hasler, T. Nussbaumer, Mechanisms and kinetics of homogeneous secondary reactions of tar from continuous pyrolysis of wood chips, Fuel. 81 (2002) 843-853. doi:http://dx.doi.org/10.1016/S0016-2361(01)00216-2.

[50] J. Neumann, N. Jäger, A. Apfelbacher, R. Daschner, S. Binder, A. Hornung, Upgraded biofuel from residue biomass by Thermo-Catalytic Reforming and hydrodeoxygenation, Biomass and Bioenergy. 89 (2016) 91-97. doi:http://dx.doi.org/10.1016/j.biombioe.2016.03.002.

[51] I.C. Kemp, Fundamentals of Energy Analysis of Dryers, in: T. Evangelos, A.S. Mujumdar (Eds.), Mod. Dry. Technol. Vol. 4 Energy Savings, Wiley-VCH, 2012: pp. 1-45. doi:10.1002/9783527631681.ch1.

[52] A. Funke, A. Niebel, D. Richter, M.M. Abbas, A.K. Müller, S. Radloff, M. Paneru, J. Maier, N. Dahmen, J. Sauer, Fast pyrolysis char - Assessment of alternative uses within the bioliq ${ }^{\circledR}$ concept, $\quad$ Bioresour. $\quad$ Technol. $200 \quad$ (2016) 905-913. doi:http://dx.doi.org/10.1016/j.biortech.2015.11.012.

[53] A. Funke, T. Demus, T. Willms, L. Schenke, T. Echterhof, A. Niebel, H. Pfeifer, N. Dahmen, Application of fast pyrolysis char in an electric arc furnace, Fuel Process. Technol. 174 (2018) 61-68. doi:10.1016/j.fuproc.2018.02.013.

[54] R. Xu, L. Ferrante, C. Briens, F. Berruti, Flash pyrolysis of grape residues into biofuel in a bubbling fluid bed, J. Anal. Appl. Pyrolysis. 86 (2009) 58-65. doi:10.1016/j.jaap.2009.04.005. 


\section{List of Figures}

Figure 1: Simplified scheme of the basic Aspen Plus simulation flowsheet ...................................... 14

Figure 2: Simplified scheme of the air pre-heating system implemented in Aspen Plus. Solid lines represent material streams, while dotted lines represent heat streams............................................ 16

Figure 3: Simplified scheme of the flue gas heating system implemented in Aspen Plus. Solid lines represent material streams, while dotted lines represent heat streams............................................ 17 Figure 4: Yields of the different product phases expressed as a mass fraction of the biomass input (asreceived basis). Solids/OC corresponds to the solids fraction present on the organic-rich condensate,

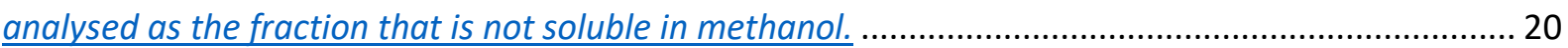

Figure 5: Organic yield expressed on a dry basis........................................................................... 22

Fiqure 6: Distribution of carbon between the product phases expressed as mass fraction of carbon input

23

Fiqure 7: Water content as a fraction of the organic-rich condensate. ............................................... 24

Figure 8: Yield of GC detectable compounds, expressed as mass fraction of biomass input (dry basis)

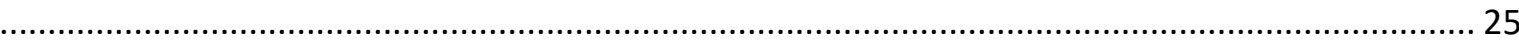

Figure 9: Percentage of the employed HE2 heat as a function of the air flow rate............................. 32

Figure 10: Efficiency of the dryer as a function of the air flow rate. ..................................................... 33

\section{List of Tables}

Table 1: Elementary and moisture content analysis of the As Received feedstock. ar: as received base,

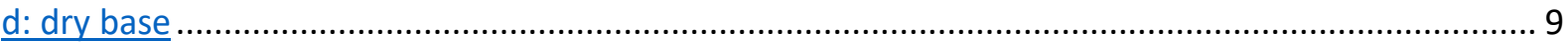

Table 2: Average moisture contents of the different feedstocks used in the trials (\% wt.). .................. 9

Table 3: Sensitivity analysis variables, their ranges, and interval ...................................................... 18

Table 4: Specific reactor heat demands per mass of feedstock $\left(\mathrm{MJ} \mathrm{kg}^{-1}\right)$......................................... 28

Table 5: Relevant heat sources and sinks resulting from Aspen simulation of the fast pyrolysis process

Table 6: Water removal and its energy demand in the dryer, the enthalpy of vapourization of water

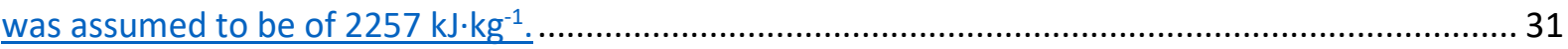

Table 7: Optimum values for the case of 'Air Drying' for all three situations in study ......................... 33

Table 8: Optimum values for the case of 'Flue Gas Drying' for all three situations in study................ 34 